FEDERAL RESERVE BANK OF SAN FRANCISCO

WORKING PAPER SERIES

\title{
Do Credit Constraints Amplify Macroeconomic Fluctuations?
}

\author{
Zheng Liu \\ Federal Reserve Bank of San Francisco \\ Pengfei Wang \\ Hong Kong University of Science and \\ Technology \\ Tao Zha \\ Federal Reserve Bank of Atlanta \\ and Emory University
}

December 2009

Working Paper 2009-28

http://www.frbsf.org/publications/economics/papers/2009/wp09-28bk.pdf

The views in this paper are solely the responsibility of the authors and should not be interpreted as reflecting the views of the Federal Reserve Bank of San Francisco or the Board of Governors of the Federal Reserve System. 


\title{
DO CREDIT CONSTRAINTS AMPLIFY MACROECONOMIC FLUCTUATIONS?
}

\author{
ZHENG LIU, PENGFEI WANG, AND TAO ZHA
}

\begin{abstract}
Previous studies on financial frictions have been unable to establish the empirical significance of credit constraints in macroeconomic fluctuations. This paper argues that the muted impact of credit constraints stems from the absence of a mechanism to explain the observed persistent comovements between housing prices and business investment. We develop such a mechanism by incorporating two key features into a DSGE model: we identify shocks that shift the demand for collateral assets and we allow productive agents to be credit-constrained. A combination of these two features enables our model to successfully generate an empirically important mechanism that amplifies and propagates macroeconomic fluctuations through credit constraints.
\end{abstract}

[T]he degree of amplification provided by credit constraints seems to depend crucially on the parameters of the economy. This sets up a clear challenge for future work: to demonstrate, in a carefully calibrated model environment, that the amplification and propagation possible by credit constraints are quantitatively significant (Kocherlakota, 2000).

Date: December 4, 2009.

Key words and phrases. Credit constraints, collateral asset, housing prices, investment, financial multiplier, business cycle, structural estimation.

JEL classification: E21, E27, E32.

For help discussions and comments, we are grateful to Susanto Basu, Larry Christiano, Marty Eichenbaum, John Fernald, Kris Gerardi, Mark Gertler, Mike Golosov, Pat Higgins, Matteo Iacoviello, Nobu Kiyotaki, Dirk Krueger, Junior Maih, Jim Nason, Lee Ohanian, Alberto Oritz-Bolanos, Richard Rogerson, Julio Rotemberg, Tom Sargent, Frank Schorfheide, Mark Spiegel, Harald Uhlig, Dan Waggoner, Carl Walsh, John Williams, and seminar participates at Federal Reserve Banks of Atlanta and San Francisco, the 2009 NBER Summer Workshop on Impulse and Propagation Mechanisms, University of Pennsylvania, University of Wisconsin, Georgetown University, UCLA, UCSD, UC Riverside, UC Santa Cruz, UC Davis, and USC. We thank David Lang, Jacob Smith, and Diego Vilan for research assistance and Anita Todd for editorial assistance. The views expressed herein are those of the authors and do not necessarily reflect the views of the Federal Reserve Banks of Atlanta and San Francisco or the Federal Reserve System. 


\section{INTRODUCTION}

In an environment with limited contract enforcement, economic agents have limited ability to borrow and loans need to be secured by collateral assets. Such credit constraints build a connection between asset prices and business investment, which provides a mechanism to amplify and propagate economic shocks and transform small shocks into large and persistent business cycle fluctuations (Kiyotaki and Moore, 1997). Although economic discussions frequently proceed as though this mechanism were quantitatively important, empirical evidence has actually been scant.

Do credit constraints amplify macroeconomic fluctuations? Existing studies find that the impact of credit constraints is muted (Kocherlakota, 2000; Cordoba and Ripoll, 2004). This finding is disappointing and indeed puzzling in light of the recent turmoil in the housing market and the concurrent deep recession. A positive answer to the question would change our way of macroeconomic modeling and our understanding of macroeconomic policy, as emphasized by Kocherlakota (2000). We show that, in the context of an estimated dynamic stochastic general equilibrium (DSGE) model, credit constraints can substantially amplify and propagate macroeconomic fluctuations.

Our model features two agents: the representative household and the representative entrepreneur. The household consumes a homogeneous good, housing services (land), and leisure and supplies labor and loanable funds in competitive markets. The entrepreneur consumes and produces the homogeneous good. Production of the good requires labor, capital, and land as inputs. To finance consumption, production, and investment, the entrepreneur borrows loanable funds subject to a credit constraint. In particular, the borrowing capacity is constrained by a fraction of the present value of land and the accumulated capital stock. Thus, land and capital serve as both inputs for production and collateral for borrowing. We use this model to demonstrate that the credit transmission mechanism elaborated by Kiyotaki and Moore (1997) is not simply theoretically elegant but empirically relevant.

We build this key empirical result in two steps. First, we observe persistent comovements between the housing price and business investment in the U.S. data. The first column of Figure 1 displays the impulse responses of the land price and business investment following a shock to the land price series. These impulse responses are estimated from a recursive bivariate Bayesian vector autoregression (BVAR) model with the Sims and Zha (1998) prior. The persistent comovements between the land price and business investment are evident. The comovements are robust to different orderings of variables and to different land (housing) price series. We focus on the land price to be consistent 
with the assumption in our theoretical model that the total supply of land is fixed. ${ }^{1}$ For credit constraints to play an important role in macroeconomic fluctuations, the model needs to be capable of explaining the observed comovements between housing prices and business investment.

Second, we identify two key determinants of these comovements: an economic shock that has direct impact on the price of collateral assets and a mechanism that propagates this shock. In the context of our theoretical model, land is an important collateral asset. Since the aggregate supply of land is fixed, shifts in housing demand influence the land price directly. But an initial impact on the land price would be insufficient to generate persistent comovements between the housing price and business investment unless there is a mechanism that propagates the initial impact.

Figure 2 illustrates this point. Suppose the economy starts from the steady state (point A) and consider the effect of a positive shock to housing demand. In the standard real business cycle (RBC) model with housing, this shock shifts the household's land demand curve upward. The land price rises and land gets redistributed from the entrepreneur to the household (from point A to point B) and there are no further actions. As land shifts away from the entrepreneur sector, business investment falls, as does the future marginal product of capital. Thus, the unconstrained model predicts negative comovements between the land price and business investment.

Consider an economy in which the entrepreneur is credit-constrained. In this case, the initial rise in the land price through the shift in the household's land demand curve raises the entrepreneur's net worth and expands the borrowing capacity. The expansion of net worth and credit shifts up the entrepreneur's land demand curve, which reinforces the household's response and results in a further rise in the land price and a further expansion of credit, generating a static financial multiplier (point C). More importantly, the rise in the entrepreneur's net worth and the expansion of credit produce a dynamic financial multiplier: more credit allows for more business investment in the current period, which means more capital stock in the future; since capital and land are complementary factors of production, more future capital stock raises future marginal product of land, which increases the current land price further,

\footnotetext{
${ }^{1}$ The land in our model can be viewed as a metaphor for assets that grow slowly or are in relatively fixed supply. Another example of such an asset is intangible capital emphasized by Bond and Cummins (2000) and Hall (2001). Davis and Heathcote (2007) show that land grows at a very slow rate and land prices are the driving force behind the rise and fall of housing prices observed in the U.S. economy. We therefore interchange the terms "land" and "housing" in the paper, as does Kocherlakota (2008).
} 
creating a ripple effect (from point $\mathrm{C}$ to point $\mathrm{E}$ ). Thus, a shift in housing demand in the credit-constrained economy has a much bigger effect on the land price and on its comovements with investment than in the unconstrained economy.

Previous literature finds muted impacts of credit constraints because it focuses on total factor productivity (TFP) shocks (Kocherlakota, 2000; Cordoba and Ripoll, 2004). A TFP shock does not have a large impact on asset prices because it moves future dividends and the risk-free interest rate in the same direction. Thus, the amplification mechanism cannot be activated by TFP shocks. TFP shocks contribute to the dynamics of aggregate output and investment through the usual channels that are familiar to a student of the RBC literature, but credit constraints do not amplify this type of shock. In general, credit constraints do not amplify nonfinancial shocks (such as the TFP shock) or financial shocks that shift the supply of an asset. ${ }^{2}$ In contrast, a shock that shifts the demand for a collateral asset generates a two-way feedback between the asset price and business investment through the channel of credit constraints. In our model, we find that housing demand shocks alone account for over $90 \%$ of the observed fluctuations in the housing price.

Previous studies fail to obtain positive comovements between housing prices and business investment because they assume a subset of households, instead of entrepreneurs (productive agents), are credit-constrained (Iacoviello and Neri, 2009). The distinction is subtle but important. Allowing entrepreneurs to be credit-constrained is an essential feature in our model for generating persistent comovements between the housing price and business investment. As the housing demand shock raises the land price, it also raises the entrepreneur's net worth and borrowing capacity, which provides an incentive for and enhances the ability of the entrepreneur to increase business investment. Through the dynamic interactions between the land price and investment made possible by credit constraints, a shock to housing demand is amplified and propagated to generate important macroeconomic fluctuations. Our estimation indicates that the housing demand shock alone accounts for $36-46 \%$ of the fluctuations in investment and $22-38 \%$ of the fluctuations in output.

The rest of the paper is organized as follows. In Section II we discuss the contribution of our paper in relation to the literature. In Section III we present the DSGE model

\footnotetext{
${ }^{2} \mathrm{~A}$ similar point is made by Christiano, Motto, and Rostagno (2008). Examples of asset supply shocks include technology shocks in the housing sector (Iacoviello and Neri, 2009) and shocks affecting the marginal efficiency of transforming investment goods into capital goods (Justiniano and Tambalotti, 2009).
} 
with credit constraints. In Section IV we analyze the model's amplification mechanism. In Section $\mathrm{V}$ we describe our estimation methodology and report the estimated results. Based on the estimated parameters and shock processes, we then discuss economic implications of the model in Section VI. Section VII concludes.

\section{RELATED Literature}

The original idea that borrowing constraints play a critical role in amplifying business cycles can be traced back at least to Fisher (1933). Our work is related to a recent strand of literature that builds on the work by Townsend (1979) and Gale and Hellwig (1985) and focuses on the costly state verification problem caused by asymmetric information between creditors and debtors. Examples includes Carlstrom and Fuerst (1997), Bernanke, Gertler, and Gilchrist (1999), Cooley, Marimon, and Quadrini (2004), De Fiore and Uhlig (2005), Gertler, Gilchrist, and Natalucci (2007), Christiano, Trabandt, and Walentin (2007), Christiano, Motto, and Rostagno (2008), and Gilchrist, Ortiz, and Zakrajsek (2009). In this class of models, as loans are priced to take into account debtors' default risks, there is an equilibrium spread between the loan rate and the deposit rate. The credit spread interacts with entrepreneurs' net worth to generate a financial accelerator: an increase in the credit spread reduces entrepreneurs' net worth and increases the default probability and the external finance premium; as the borrowing cost rises, entrepreneurs choose to reduce borrowing and cut investment and these actions increase the credit spread further.

Similar to the financial multiplier in Kiyotaki and Moore (1997), the financial accelerator in Bernanke, Gertler, and Gilchrist (1999) can potentially amplify macroeconomic fluctuations. In recent papers, Christiano, Trabandt, and Walentin (2007) and Christiano, Motto, and Rostagno (2008) examine the empirical importance of the financial accelerator using time series data from the United States and the Euro Area; they identify certain financial shocks as demand shifters that drive the fluctuations in both the external finance premium and investment. This approach, however, is not designed to address credit or liquidity constraints (i.e, limited participation in the capital market) or questions related to dynamic interactions between collateral prices and business investment. 
To address these questions, our model builds on the recent literature that focuses on the costly contract enforcement problem (i.e., the problem of controlling over assets) instead of the costly state verification problem. ${ }^{3}$ A partial list of works in this literature includes Kiyotaki and Moore (1997), Kiyotaki (1998), Kocherlakota (2000), Krishnamurthy (2003), Cordoba and Ripoll (2004), Iacoviello (2005), Lorenzoni (2008), Pintus and Wen (2008), and Iacoviello and Neri (2009). ${ }^{4}$ In this class of models, as in our model, the debtor's borrowing capacity is constrained by the value of his or her collateral assets. If productive agents are constrained by credit, the price of a collateral asset directly interacts with the debt level and therefore with investment and output. Such an interaction can, in theory, generate a financial multiplier that amplifies business cycle shocks. What is new in this paper is that we establish the empirical significance of credit constraints and make the theory of credit constraints relevant to practical economic problems. To get a strong amplification effect, moreover, we match the observed comovements between the housing price and business investment by identifying an economic shock that directly shifts the demand for housing and an economic mechanism that sustains and propagates this shock.

The amplification mechanism developed in this paper builds on an externality made possible by credit constraints. When deciding on how much to borrow and how much to invest, each individual entrepreneur takes as given asset prices, and in particular, the land price. The entrepreneurs respond to changes in the land price by raising their optimal levels of debt and investment and they do not take into account the consequences of their collective investment decisions on the land price. Thus, following a positive shift in housing demand, the land price rises; as entrepreneurs are constrained by credit, the rise in the land price generates a wealth effect for each individual entrepreneur so that she chooses to expand the levels of debt and investment. In a competitive equilibrium, as all entrepreneurs make identical decisions, aggregate investment rises, driving up the demand for land and the land price, leading to a further expansion of debt and investment. Following a negative shock, the cycle reverses directions, and the credit constraint generates a downward spiral in the land price and investment. This type of externality or strategic complementarity leads to inefficient credit booms and busts, a

\footnotetext{
${ }^{3}$ The two approaches are complementary, however. For certain economic questions, it would be desirable to combine them in one single model (Aoki, Proudman, and Vlieghe, 2004; Gertler and Kiyotaki, 2009).

${ }^{4}$ Open-economy extensions of this class of models include Aoki, Benigno, and Kiyotaki (2007) and Mendoza (2008) among others.
} 
feature similar to that studied by Lorenzoni (2008) in a three-period model with credit constraints. We show that this feature with credit booms and busts can be generalized to a fully articulated DSGE model and the amplification effect is quantitatively important.

\section{THE MODEL}

The economy consists of two agents - the representative household and the representative entrepreneur. There are four types of commodities: labor, goods, land, and loanable bonds. Goods production requires labor, capital, and land as inputs. The output can be used for consumption (by both types of agents) and for capital investment (by the entrepreneurs). The representative household's utility depends on consumption goods, land services (housing), and leisure; the representative entrepreneur's utility depends on consumption goods only. We assume that the household is more patient than the entrepreneur so that the collateral constraint is binding in and near the steady-state equilibrium..$^{5}$

III.1. The representative household. Similar to Iacoviello (2005), the household has the utility function

$$
\mathrm{E} \sum_{t=0}^{\infty} \beta^{t} A_{t}\left\{\log \left(C_{h t}-\gamma_{h} C_{h, t-1}\right)+\varphi_{t} \log L_{h t}-\psi_{t} N_{h t}\right\},
$$

where $C_{h t}$ denotes consumption, $L_{h t}$ denotes land holdings, and $N_{h t}$ denotes labor hours. The parameter $\beta \in(0,1)$ is a subjective discount factor, the parameter $\gamma_{h}$ measures the degree of habit persistence, and the term $\mathrm{E}$ is a mathematical expectation operator. The term $A_{t}$ represent a shock to the household's patience factor, $\varphi_{t}$ a shock to housing demand, and $\psi_{t}$ a shock to labor supply. We assume that the intertemporal preference shock $A_{t}$ follows the stochastic process

$$
A_{t}=A_{t-1}\left(1+\lambda_{a t}\right), \quad \ln \lambda_{a t}=\left(1-\rho_{a}\right) \ln \bar{\lambda}_{a}+\rho_{a} \ln \lambda_{a, t-1}+\varepsilon_{a t},
$$

where $\bar{\lambda}_{a}>0$ is a constant, $\rho_{a} \in(-1,1)$ is the persistence parameter, and $\varepsilon_{a t}$ is an identically and independently distributed (i.i.d.) white noise process with mean zero

\footnotetext{
${ }^{5}$ In Liu, Wang, and Zha (2009a), we provide a micro-foundation for the representative household's patience factor. In particular, we consider an economy with heterogeneous households and entrepreneurs, where the households face uninsurable idiosyncratic income risks and thus have a precautionary motive for saving. We show that the desire for precautionary saving will make the households appear more patient than the entrepreneurs at the aggregate level, provided that the households face more persistent idiosyncratic shocks than do the entrepreneurs.
} 
and variance $\sigma_{a}^{2}$. The housing preference shock $\varphi_{t}$ follows the stationary process

$$
\ln \varphi_{t}=\left(1-\rho_{\varphi}\right) \ln \bar{\varphi}+\rho_{\varphi} \ln \varphi_{t-1}+\varepsilon_{\varphi t},
$$

where $\bar{\varphi}>0$ is a constant, $\rho_{\varphi} \in(-1,1)$ measures the persistence of the shock, and $\varepsilon_{\varphi t}$ is a white noise process with mean zero and variance $\sigma_{\varphi}^{2}$. The labor supply shock $\psi_{t}$ follows the stationary process

$$
\ln \psi_{t}=\left(1-\rho_{\psi}\right) \ln \bar{\psi}+\rho_{\psi} \ln \psi_{t-1}+\varepsilon_{\psi t},
$$

where $\bar{\varphi}>0$ is a constant, $\rho_{\psi} \in(-1,1)$ measures the persistence, and $\left.\varepsilon_{\psi t}\right)$ is a white noise process with mean zero and variance $\sigma_{\psi}^{2}$.

Denote by $q_{l t}$ the relative price of housing (in consumption units), $R_{t}$ the gross real loan rate, and $w_{t}$ the real wage; denote by $S_{t}$ the household's purchase in period $t$ of the loanable bond that pays off one unit of consumption good in all states of nature in period $t+1$. In period 0 , the household begins with $L_{h,-1}>0$ units of housing and $S_{-1}>0$ units of the loanable bond. The flow of funds constraint for the household is given by

$$
C_{h t}+q_{l t}\left(L_{h t}-L_{h, t-1}\right)+\frac{S_{t}}{R_{t}} \leq w_{t} N_{h t}+S_{t-1}
$$

The household chooses $C_{h t}, L_{h, t}, N_{h t}$, and $S_{t}$ to maximize (1) subject to (2)-(5) and the borrowing constraint $S_{t} \geq-\bar{S}$ for some large number $\bar{S}$.

III.2. The representative entrepreneur. The entrepreneur has the utility function

$$
\mathrm{E} \sum_{t=0}^{\infty} \beta^{t}\left[\log \left(C_{e t}-\gamma_{e} C_{e, t-1}\right)\right],
$$

where $C_{e t}$ denotes the entrepreneur's consumption and $\gamma_{e}$ is the habit persistence parameter.

The entrepreneur produces goods using capital, labor, and land as inputs. The production function is given by

$$
Y_{t}=Z_{t}\left[L_{e, t-1}^{\phi} K_{t-1}^{1-\phi}\right]^{\alpha} N_{e t}^{1-\alpha},
$$

where $Y_{t}$ denotes output, $K_{t-1}, N_{e t}$, and $L_{e, t-1}$ denote the inputs capital, labor, and land, respectively, and the parameters $\alpha \in(0,1)$ and $\phi \in(0,1)$ measure the output elasticities of these production factors. We assume that the total factor productivity $Z_{t}$ is composed of a permanent component $Z_{t}^{p}$ and a transitory component $\nu_{t}$ such that $Z_{t}=Z_{t}^{p} \nu_{z t}$, where the permanent component $Z_{t}^{p}$ follows the stochastic process

$$
Z_{t}^{p}=Z_{t-1}^{p} \lambda_{z t}, \quad \ln \lambda_{z t}=\left(1-\rho_{z}\right) \ln \bar{\lambda}_{z}+\rho_{z} \ln \lambda_{z, t-1}+\varepsilon_{z t},
$$


and the transitory component follows the stochastic process

$$
\ln \nu_{z t}=\rho_{\nu_{z}} \ln \nu_{z, t-1}+\varepsilon_{\nu_{z} t} .
$$

The parameter $\bar{\lambda}_{z}$ is the steady-state growth rate of $Z_{t}^{p}$; the parameters $\rho_{z}$ and $\rho_{\nu_{z}}$ measure the degree of persistence. The innovations $\varepsilon_{z t}$ and $\varepsilon_{\nu_{z} t}$ are i.i.d. white noise processes that are mutually independent with mean zero and variances given by $\sigma_{z}^{2}$ and $\sigma_{\nu_{z}}^{2}$, respectively.

The entrepreneur is endowed with $K_{-1}$ units of initial capital stock and $L_{e,-1}$ units of initial land. Capital accumulation follows the law of motion

$$
K_{t}=(1-\delta) K_{t-1}+\left[1-\frac{\Omega}{2}\left(\frac{I_{t}}{I_{t-1}}-\bar{\lambda}_{I}\right)^{2}\right] I_{t},
$$

where $I_{t}$ denotes investment, $\bar{\lambda}_{I}$ denotes the steady-state growth rate of investment, and $\Omega>0$ is the adjustment cost parameter.

The entrepreneur faces the flow of funds constraint

$$
C_{e t}+q_{l t}\left(L_{e t}-L_{e, t-1}\right)+B_{t-1}=Z_{t}\left[L_{e, t-1}^{\phi} K_{t-1}^{1-\phi}\right]^{\alpha} N_{e t}^{1-\alpha}-\frac{I_{t}}{Q_{t}}-w_{t} N_{e t}+\frac{B_{t}}{R_{t}},
$$

where $B_{t-1}$ is the amount of matured debt and $B_{t} / R_{t}$ is the value of new debt. Following Greenwood, Hercowitz, and Krusell (1997), we interpret $Q_{t}$ as the investment-specific technological change. Specifically, we assume that $Q_{t}=Q_{t}^{p} \nu_{q t}$, where the permanent component $Q_{t}^{p}$ follows the stochastic process

$$
Q_{t}^{p}=Q_{t-1}^{p} \lambda_{q t}, \quad \ln \lambda_{q t}=\left(1-\rho_{q}\right) \ln \bar{\lambda}_{q}+\rho_{q} \ln \lambda_{q, t-1}+\varepsilon_{q t},
$$

and the transitory component $\mu_{t}$ follows the stochastic process

$$
\ln \nu_{q t}=\rho_{\nu_{q}} \ln \nu_{q, t-1}+\varepsilon_{\nu_{q} t}
$$

The parameter $\bar{\lambda}_{q}$ is the steady-state growth rate of $Q_{t}^{p}$; the parameters $\rho_{q}$ and $\rho_{\nu_{q}}$ measure the degree of persistence. The innovations $\varepsilon_{q t}$ and $\varepsilon_{\nu_{q} t}$ are i.i.d. white noise processes that are mutually independent with mean zero and variances given by $\sigma_{q}^{2}$ and $\sigma_{\nu_{q}}^{2}$, respectively.

The entrepreneur faces the credit constraint

$$
B_{t} \leq \theta_{t} E_{t}\left[q_{l, t+1} L_{e t}+q_{k, t+1} K_{t}\right]
$$

where $q_{k, t+1}$ is the shadow price of capital in consumption units. ${ }^{6}$ Under this credit constraint, the amount that the entrepreneur can borrow is limited by a fraction of the

\footnotetext{
${ }^{6}$ Since the price of new capital is $1 / Q_{t}$, Tobin's q in this model is given by $q_{k t} Q_{t}$, which is the ratio of the value of installed capital to the price of new capital.
} 
value of the collateral assets - land and capital. Following Kiyotaki and Moore (1997), we interpret this type of credit constraint as reflecting the problem of costly contract enforcement: if the entrepreneur fails to pay the debt, the creditor can seize the land and the accumulated capital; since it is costly to liquidate the seized land and capital stock, the creditor can recoup up to a fraction $\theta_{t}$ of the total value of collateral assets. ${ }^{7}$ We interpret $\theta_{t}$ as a "collateral shock" that reflects the uncertainty in the tightness of the credit market. We assume that $\theta_{t}$ follows the stochastic process

$$
\ln \theta_{t}=\left(1-\rho_{\theta}\right) \ln \bar{\theta}+\rho_{\theta} \ln \theta_{t-1}+\varepsilon_{\theta t},
$$

where $\bar{\theta}$ is the steady-state value of $\theta_{t}, \rho_{\theta} \in(0,1)$ is the persistence parameter, and $\varepsilon_{\theta t}$ is an i.i.d. white noise process with mean zero and variance $\sigma_{\theta}^{2}$.

The entrepreneur chooses $C_{e t}, N_{e t}, I_{t}, L_{e, t}, K_{t}$, and $B_{t}$ to maximize (6) subject to (7) through (15).

III.3. Market clearing conditions and equilibrium. In a competitive equilibrium, the markets for goods, labor, land, and loanable bonds all clear. The goods market clearing condition implies that

$$
C_{t}+\frac{I_{t}}{Q_{t}}=Y_{t}
$$

where $C_{t}=C_{h t}+C_{e t}$ denotes aggregate consumption. The labor market clearing condition implies that labor demand equals labor supply:

$$
N_{e t}=N_{h t} \equiv N_{t}
$$

The land market clearing condition implies that

$$
L_{h t}+L_{e t}=\bar{L}
$$

where $\bar{L}$ is the fixed aggregate land endowment. Finally, the bond market clearing condition implies that

$$
S_{t}=B_{t}
$$

A competitive equilibrium consists of sequences of prices $\left\{w_{t}, q_{l t}, R_{t}\right\}_{t=0}^{\infty}$ and allocations $\left\{C_{h t}, C_{e t}, I_{t}, N_{h t}, N_{e t}, L_{h t}, L_{e t}, S_{t}, B_{t}, K_{t}, Y_{t}\right\}_{t=0}^{\infty}$ such that (i) taking the prices as given, the allocations solve the optimizing problems for the household and the entrepreneur and (ii) all markets clear.

\footnotetext{
${ }^{7}$ Under some conditions, this type of credit constraints can be consistent with an optimal contract (Lorenzoni and Walentin, 2007).
} 


\section{Understanding the Model}

Before we present the quantitative results, it is useful to explain the model's transmission mechanism. As we have alluded to in the introduction, credit constraints do not amplify non-financial shocks such as TFP shocks or financial shocks that shift the supply of assets. TFP shocks cannot be amplified by credit constraints because these shocks do not have large impacts on the prices of collateral assets. Shocks that shift asset supply cannot be propagated through credit constraints because these shocks generate negative comovements between asset prices and investment. In contrast, shocks that shift asset demand can generate positive comovements between asset prices and real aggregate variables and thus can be amplified and propagated through credit constraints.

In our model, there are two types of financial shocks that shift the demand for collateral assets: the collateral shock and the housing demand shock. We now illustrate the transmission mechanism of each of these two types of shocks.

Consider the intertemporal Euler equations for land holdings by the household and the entrepreneur:

$$
\begin{aligned}
q_{l t} & =\beta \mathrm{E}_{t} \frac{C_{h t}}{C_{h, t+1}} q_{l, t+1}+\frac{A_{t} \varphi_{t} C_{h t}}{L_{h t}} \\
q_{l t} & =\beta \mathrm{E}_{t} \frac{C_{e t}}{C_{e, t+1}}\left[\alpha \phi \frac{Y_{t+1}}{L_{e t}}+q_{l, t+1}\right]+\frac{\mu_{b t}}{\mu_{e t}} \theta_{t} \mathrm{E}_{t} q_{l, t+1},
\end{aligned}
$$

where, for simplicity, we abstract from habit formation by setting $\gamma_{h}=\gamma_{e}=0$ and the term $\frac{\mu_{b t}}{\mu_{e t}}$ in $(21)$ is the shadow value of the entrepreneur's existing loans (in consumption units), which is strictly positive if and only if the credit constraint is binding.

Equation (20) describes the optimal land-holding decision by the household. The cost of acquiring a marginal unit of land is $q_{l t}$ units of consumption goods; the benefit of having the marginal unit of land, which is summarized on the right-hand-side of (20), consists of the marginal utility of housing services (in consumption units) and the discounted resale value of land. At the margin, the marginal cost equals the marginal benefit. Equation (21) describes a similar optimal land-holding decision by the entrepreneur. Here, however, since the entrepreneur is credit-constrained, acquiring a marginal unit of land not only yields benefits from the future marginal product of land and the resale value, but also from the shadow value of land as a collateral asset.

These Euler equations can be intuitively thought of as the land demand equations by the two types of agents. Figure 2 plots the land demand curves of the two agents; that is, the static relation between the current land price $q_{l t}$ and the current quantity of 
land held by the household $\left(L_{h t}\right)$ and the relation between $q_{l t}$ and the quantity of land held by the entrepreneur $\left(L_{e t}\right)$. In plotting these land demand curves, we treat other variables such as the future land price, consumption growth, the marginal product of land, and exogenous shocks as shift factors. Land is of fixed supply and allocated between the household and the entrepreneur. We assume that the initial equilibrium is the steady state (Point A).

IV.1. Effects of a collateral shock. Consider first the effects of a persistent positive collateral shock that expands the entrepreneur's borrowing capacity for any given value of the collateral (i.e., a persistent increase in $\theta_{t}$ in $(21)$ ). The collateral shock raises the marginal value of land as collateral and, according to (21), shifts the entrepreneur's land demand curve upward. In consequence, the land price rises and land gets reallocated from the household to the entrepreneur. The increase in land holdings by the entrepreneur raises future marginal products of capital and thus current investment. The increase in investment leads to a rise in future capital stocks and future marginal products of land, which increase the entrepreneur's current land demand further. Thus, through the credit constraint, the collateral shock generates a multiplier that can potentially amplify and propagate the initial shock.

The amplification effects of the collateral shock, however, are partly offset by the entrepreneur's increased leverage when the borrowing capacity expands. The rise in debt liability reduces the entrepreneur's future net worth and thus dampens the initial rise in land demand and the land price. Furthermore, since the collateral shock does not shift the household's land demand curve, it does not trigger competing demand for land between the two sectors. In consequence, it is difficult for the collateral shock to generate a strong reaction in the land price and a strong financial multiplier.

IV.2. Effects of a housing demand shock. Shocks to housing demand are much more promising in generating a strong financial multiplier. Like collateral shocks, housing demand shocks are an asset-demand shifter and are thus capable of generating positive comovements between the land price and business investment. Unlike the collateral shock, however, a housing demand shock that raises the household's marginal utility of housing and land demand also raises the entrepreneur's net worth and land demand, triggering competing demand for land between the two sectors that drives up the land price.

More specifically, consider the effects of a persistent positive shock to the housing demand (i.e., a persistent increase in $\varphi_{t}$ in (20)). The shock raises the marginal utility 
of housing and shifts the household's land demand curve upward. In consequence, the land price rises and land gets redistributed from the entrepreneur to the household. In an RBC model with housing but without credit constraints, the new equilibrium would be established at point B and there would be no further actions. Thus, a housing demand shock would lead to a rise in the land price. But the redistribution of land from production to consumption reduces business investment, leading to a negative comovement between the land price and investment. This result from the RBC model would be inconsistent with the data.

Now consider the economy with the entrepreneur constrained by credit. The initial rise in the land price raises the entrepreneur's net worth, which shifts up the entrepreneur's land demand curve. As the entrepreneur competes with the household for land, the land price increases further and so does the entrepreneur's net worth. The rise in the entrepreneur's net worth shifts the entrepreneur's land demand further, generating a static financial multiplier (point $\mathrm{C}$ ). The persistent rise in the land price produces also a dynamic multiplier: the higher collateral value implies an expanded credit limit, which allows for more business investment in the current period and help accumulate more capital stock in the future; since capital and land are complementary factors of production, more capital stock raises future marginal products of land, which increase the current land price further (from point $\mathrm{C}$ to point $\mathrm{E}$ ). Thus, unlike the collateral shock, the initial shift in housing demand can lead to a large rise in both the land price and business investment.

IV.3. What is the housing demand shock? Given the central role the housing demand shock plays in our model, it is useful to discuss what this type of financial shock might represent. One interpretation is that the housing demand shock simply represents an exogenous shift in the household's taste for housing services. Iacoviello and Neri (2009) present evidence that supports this view.

Another interpretation is that the shock in our stylized aggregate model, like any shocks in the model including different technology shocks, is a reduced form representation of frictions or some "deeper" shocks that are outside of the model. In Liu, Wang, and Zha (2009b), we present a theory of the housing demand shock. In particular, we consider an economy with heterogeneous households who experience idiosyncratic and uninsurable liquidity shocks and who face collateral constraints in borrowing. In the aggregated version of that model, there is a term in the housing Euler equation that corresponds to the housing demand shock in our current model. We show that this term is a decreasing function of the tightness of the collateral constraints (i.e., the 
loan-to-value ratios) at the micro-level. Thus, financial innovations or de-regulations that relax the households' collateral constraints and expand the households' borrowing capacity in the disaggregated model would translate into a positive housing demand shock at the aggregate level.

\section{BAYESIAN ESTIMATION}

We use the Bayesian method to fit our model to quarterly U.S. time series data. In this section, we describe the data, our strategies for estimating the model, and our estimation results.

V.1. The data. The time series that we use include the relative price of land, the inverse of the quality-adjusted relative price of investment, real per capita consumption, real per capita investment (in consumption units), real per capita nonfarm and nonfinancial business debt, and per capita hours worked (as a fraction of total time endowment). ${ }^{8}$ The sample covers the period from 1975:Q1 to 2009:Q3.

V.2. Priors for parameters. We partition the model parameters into three subsets. The first subset of parameters includes the structural parameters on which we have agnostic priors. This set of parameters, summarized in the vector $\Psi_{1}=$ $\left\{\gamma_{h}, \gamma_{e}, \Omega, g_{\gamma}, \bar{\lambda}_{q}\right\}$, consists of the habit persistence parameters $\gamma_{h}$ and $\gamma_{e}$, investmentadjustment cost parameter $\Omega$, the growth rate of per capita output $g_{\gamma}$, and the growth rate of per capita investment $\bar{\lambda}_{q}$. These parameters are listed in the top panel of Table 1.

We assume that the priors for $\gamma_{h}$ and $\gamma_{e}$ follow the beta distribution with the shape parameters given by $a=1$ and $b=2$. Thus, we assign positive density to $\gamma_{h}=\gamma_{e}=0$ and let the probability density decline linearly as the value of $\gamma_{h}$ (or $\gamma_{e}$ ) increases from 0 to 1 . These hyper-parameter values imply that a lower probability (5\%) bound for $\gamma_{h}$ and $\gamma_{e}$ is 0.0256 and an upper probability (95\%) bound is 0.7761 . This $90 \%$ probability interval covers most calibrated values for the habit persistence parameter used in the literature (e.g., Boldrin, Christiano, and Fisher (2001) and Christiano, Eichenbaum, and Evans (2005)). The prior for the investment adjustment cost parameter $\Omega$ follows the gamma distribution with the shape parameter $a=1$ and the rate parameter $b=0.5$.

\footnotetext{
${ }^{8}$ Appendix A describes the details of our data. The data on investment-specific technology are needed to get the sizes of standard deviations of investment technology shocks in line with those in Krusell, Ohanian, Ríos-Rull, and Violante (2000) and Fisher (2006). By using an explicit measure of investment-specific technology shocks (i.e., biased technology shocks) in our estimation, we will be able to assess the importance of biased technology shocks relative to neutral technology shocks.
} 
These hyper-parameters imply that the probability density at $\Omega=0$ is positive and that the $90 \%$ prior probability interval for $\Omega$ ranges from 0.1 to 6 , which covers most values used in the DSGE literature (e.g., Christiano, Eichenbaum, and Evans (2005), Smets and Wouters (2007), and Liu, Waggoner, and Zha (2009)). The priors for the steady-state growth rates of output and of capital follow the gamma distribution with the $90 \%$ probability interval covering the range between 0.1 and 1.5 , corresponding to annual growth rates between $0.4 \%$ and $6 \%$.

The second subset of parameters includes the structural parameters for which we use the steady-state relations for constructing informative priors. This set of parameters, summarized in the vector $\Psi_{2}=\left\{\beta, \bar{\lambda}_{a}, \bar{\varphi}, \bar{\psi}, \phi, \alpha, \theta, \delta\right\}$, consists of the subjective discount factor $\beta$, the patience factor $\bar{\lambda}_{a}$, the housing preference parameter $\bar{\varphi}$, the leisure preference parameter $\bar{\psi}$, the elasticity parameters in the production function $\phi$ and $\alpha$, the average loan-to-asset ratio $\theta$, and the capital depreciation rate $\delta$.

To construct the prior distributions for the parameters in $\Psi_{2}$, we first simulate the parameters in $\Psi_{1}$ from their prior distributions and then, for each simulation, we impose the steady-state restrictions on both $\Psi_{1}$ and $\Psi_{2}$ such that the model matches the following moment conditions: (1) the average labor income share is $70 \%$ ( $\alpha=$ $0.3)$; (2) the average real prime loan rate is $4 \%$ per annum (Huggett, Ventura, and Yaron, 2009); (3) the capital-output ratio is on average 1.15 at the annual frequency; (4) the investment-capital ratio is on average 0.209 at the annual frequency; (5) the average land-output ratio is 0.65 at the annual frequency; (6) the average nonfarm and nonfinancial businesses' loan-asset ratio is 0.75 at the annual frequency $(\theta=0.75)$; (7) the average housing-output ratio is 1.45 at the annual frequency; and (8) the average market hours is $25 \%$ of time endowment. ${ }^{9}$ Since the prior distributions for the parameters in $\Psi_{2}$ are of unknown form, the $90 \%$ probability bounds, reported in Table 1 (the lower panel), are generated through simulations. As shown in the table, the steady-state restrictions lead to informative probability intervals for the marginal

\footnotetext{
${ }^{9}$ Since we have a closed-economy model with no government spending, we measure private domestic output by the sum of personal consumption expenditures and private domestic investment, where consumption is the expenditures on nondurable goods and non-housing services, and investment is the expenditures on consumer durable goods and fixed investment in equipment and software. These time series are provided by the Bureau of Economic Analysis (BEA) through Haver Analytics. Capital and housing stock are in annual rates. Capital stock includes the annual stocks of equipment, software, and consumer durable goods. The land-output ratio is the ratio of the nominal value of land input and the nominal value of output in the private nonfarm and nonfinancial business sector for the period 1987-2007 taken from the Bureau of Labor Statistics (BLS).
} 
prior distributions of the parameters and thus help identify the structural parameters in $\Psi_{2} \cdot{ }^{10}$ Our method for constructing the prior distributions for $\Psi_{2}$ is similar to the approach studied by Del Negro and Schorfheide (2008), which combines the Baynesian approach and the standard calibration approach for eliciting priors.

The third subset of parameters consists of those describing the shock processes displayed in Table 2. These parameters are summarized by $\Psi_{3}=\left\{\rho_{i}, \sigma_{i}\right\}$ for $i \in$ $\left\{a, z, \nu_{z}, q, \nu_{q}, \varphi, \psi, \theta\right\}$, where $\rho_{i}$ and $\sigma_{i}$ denote the persistence parameters and the standard deviations of the eight structural shocks. As for the parameters in $\Psi_{1}$, we adopt agnostic priors for these parameters in $\Psi_{3} \cdot{ }^{11}$

V.3. Posterior estimates. Table 1 reports the estimates of structural parameters at the posterior mode, along with the $90 \%$ probability intervals for each estimated parameter based on the posterior distributions (the last 3 columns).

The upper panel reports the estimated values of the parameters in $\Psi_{1}$. Both types of agents have only modest degrees of habit persistence, with the entrepreneur's habit parameter somewhat larger than the household's (0.61 vs. 0.47). The probability interval for the entrepreneur's habit parameter is much wider than that for the household's habit parameter. Both parameters are statistically significant.

In our model with credit constraints, explicit costs of investment adjustment turned out to be unimportant, with the estimated adjustment cost parameter $(\Omega=0.19)$ much smaller than the values obtained in the literature. ${ }^{12}$ The probability interval around this low estimate is tight. We obtain this sharp result because, unlike Smets and Wouters (2007) and Justiniano and Primiceri (2008) who treat the investment-specific shock as a latent time series, we fit our model to the time series of the relative price

\footnotetext{
${ }^{10}$ Even with a subset of deep parameters well identified, the posterior density function is still very non-Gaussian and has many local peaks. For example, one would get estimates at a much lower peak when using Dynare mechanically. We randomly simulate 100000 starting points and select the converged result that gives the highest posterior density. Among these starting points, many converge to the point that has the highest peak. The computing time is about 4-5 days on a cluster of 24 $2.5 \mathrm{GHz}$ computers.

${ }^{11}$ Specifically, the priors for the persistent parameters follow the beta distribution with the $90 \%$ probability interval given by $[0.0256,0.7761]$; the priors for the standard deviations follow the inverse gamma distribution with the $90 \%$ probability interval given by $[0.0001,1.0]$. We have examined the sensitivity of our estimates by extending both the lower and the upper bounds of this interval and found that the results are not sensitive.

${ }^{12}$ The literature reports the estimates of the investment-adjustment cost parameter between 2.5 and 6 (Christiano, Eichenbaum, and Evans, 2005; Smets and Wouters, 2007).
} 
of investment. Consequently, we obtain smaller standard deviations of the investmentspecific shock (see Table 2).

Per capita output is estimated to grow at an annual rate of about $1.5 \%$, consistent with the average growth rate of real per capita GDP in the United States for the postwar period. The investment-specific technology (IST) grows at a much faster annual rate of about 5\%, consistent with the calibration by Greenwood, Hercowitz, and Krusell (1997). Indeed, our estimated growth rate of the IST is higher than that calibrated by Greenwood, Hercowitz, and Krusell (1997), who use a shorter sample that ends in 1990. For the sub-sample after the early 1990s, however, the United States economy experienced even more rapid declines in the quality-adjusted relative price of equipment, software, and consumer durable goods. The $90 \%$ probability intervals for all the parameters in $\Psi_{1}$ indicate that these parameters are tightly estimated.

The lower panel of Table 1 reports the estimated values of the parameters in $\Psi_{2}$, along with the $90 \%$ probability intervals. ${ }^{13}$ For this set of parameters, we impose the steady-state relations to help identification. The $90 \%$ probability intervals for the posterior estimates are much tighter than those for the priors. The estimated patience factor (0.0068) implies that the first-order excess return (i.e., the steady-state return from investment less the steady-state loan rate) is about $2.75 \%$ per annum. Thus, the entrepreneur assigns a substantial premium to existing loans.

Table 2 displays the estimates of the parameters in the shock processes at the posterior mode and the $90 \%$ posterior probability intervals. Both permanent and transitory technology shocks have smaller standard deviations than non-technology shocks. This difference remains when the probability intervals are taken into account.

\section{ECONOMIC IMPLICATIONS}

We now examine economic implications of the model's transmission mechanism based on the estimated parameters. We first demonstrate the amplification mechanism of credit constraints through impulse responses of several key macroeconomic variables following various shocks. In particular, we show that credit constraints amplify financial shocks that shift the demand for collateral assets, but they do not amplify non-financial shocks such as the TFP shock (Section VI.1). We then examine the relative importance of each shock in driving fluctuations in asset prices and macroeconomic aggregates through variance decompositions (Section VI.2). Finally, we examine the quantitative

\footnotetext{
${ }^{13}$ The last two rows of the table reports the calibrated values of $\alpha$ and $\bar{\theta}$ to match the average labor income share 0.7 and the average loan-to-value ratio 0.75 .
} 
importance of the model's propagation mechanism. In particular, we demonstrate that the model driven solely by financial shocks is able to explain most of the observed comovements between the land price and investment (Section VI.3).

VI.1. Amplification made possible by credit constraints. In our model, the entrepreneur's credit limit is endogenous, depending on the collateral value and hence on the price of the collateral asset. A shock can be amplified through credit constraints if it can move this asset price, triggering a financial multiplier. We now examine the importance of this endogenous credit limit and thus the ability of credit constraints to amplify economic shocks. We do this by plotting impulse responses of several key macroeconomic variables in our estimated model and comparing these responses to those obtained in a counterfactual economy in which the credit limit is fixed exogenously at the steady-state level.

Our analysis indicates that the strength of amplification depends both on how responsive the price of a collateral asset is to the shock and on the internal transmission mechanism, not necessarily on the persistence of a shock alone. A shock to neutral technology growth is a permanent shock to the level of technology and is thus very persistent. But such a permanent shock generates little effect on the financial multiplier. Figure 3 indicates that the impulse responses of macroeconomic variables to a shock to neutral technology growth in the economy with endogenous credit constraints (solid lines) are not much different from those in the economy with fixed credit limits (dashed lines). Indeed, the impulse responses in the counterfactual economy with fixed credit limits lie well within the standard error bands of the impulse responses estimated in our benchmark model with endogenous credit limits. This result confirms the similar finding by Kocherlakota (2000) and Cordoba and Ripoll (2004) that a TFP shock generates weak effect on the financial multiplier. Since technology shocks move the dividends (i.e., the rental values of land) and the discount rate (i.e., the loan rate) in the same direction, they do not generate large fluctuations in the price of the collateral asset and therefore do not have significant effects on the borrowing capacity.

The borrowing capacity is influenced mainly by two sources of financial shocks: the collateral shock that directly affects the borrowing capacity and the housing demand shock that indirectly affects the borrowing capacity by moving the land price. To assess the quantitative importance of the transmission mechanism provided by the credit constraint, we plot the impulse responses of several key variables following each of these two financial shocks. 
Figure 4 displays the impulse responses of four macroeconomic variables to a positive collateral shock. The amplification effect is evident: compared to the economy with the fixed credit limit, the estimated peak response of output in our model with the endogenous credit constraint is more than three times as large. The responses of the land price, consumption, and investment are all amplified under the endogenous credit constraint. The differences in impulse responses between the economy with the endogenous credit constraint and the economy with the fixed credit constraint are considerable, as the responses for the economy with the fixed credit constraint lie mostly outside of the standard error bands of estimated impulse responses. This finding is consistent with the common belief that a financial shock to the borrowing constraint matters to macroeconomic variables (Chaney, Sraer, and Thesmar, 2008; Jermann and Quadrini, 2009).

Figures 5 displays the impulse responses to a positive housing demand shock. Similar to the collateral shock, the housing demand shock generates hump-shaped responses of the macroeconomic variables and the shock is amplified substantially through the endogenous credit constraint. Compared to the economy where the credit limit is exogenously fixed (thick dashed lines), the estimated responses of investment and output to the housing demand shock are at least three times as large (solid lines). Again, judged by the standard error bands of impulse responses, the differences in impulse responses between the economy with the endogenous credit constraint and the economy with the fixed credit constraint are statistically significant.

VI.2. Relative importance of different shocks. What lacks in the literature is a general-equilibrium analysis of the relative importance of each shock in driving the dynamics of several key macroeconomic variables, especially the relative importance of each of the two types of financial shocks. As we have argued, a large and persistent exogenous shock does not necessarily have a large and persistent impact on asset prices and real variables. Whether an economic shock has a significant impact on the equilibrium dynamics depends not only on the size and persistence of the shock itself but also on the model's internal transmission mechanism.

To take into account the model's internal transmission mechanism and gauge the relative importance of each shock, we use the variance decomposition method. Table 3 reports the variance decompositions for the land price and aggregate quantities across the eight types of structural shocks at forecasting horizons between the impact period (1Q) and six years after the shock (24Q). 
We begin with the patience shock, which is persistent and has the largest standard deviation (almost four times the size of the second largest shock). Despite its persistence and large size, the patience shock has a very small impact on the dynamics of the land price. It has some impacts on investment (about 20\%) and on output (about 10\%). Similarly, we have two neutral technology shocks or TFP shocks, one is permanent (and thus most persistent) and the other one is transitory. Both shocks account for little of the fluctuations in the land price but both, especially the shock to the growth rate, account for a substantial fraction of fluctuations in consumption (about 55\%) and in output $(10-36 \%)$ at business cycle frequencies. These findings are consistent with Kocherlakota (2000) and Cordoba and Ripoll (2004), who report weak financial multiplier effects following TFP a shock in a model with credit constraints. TFP shocks do drive business cycle fluctuations, but they do not work through the financial channel created by credit constraints because these shocks do not move the asset prices much.

In contrast, the housing demand shock, which has the second largest standard deviation and is very persistent, stands out as the most important source of the fluctuations in the land price: it accounts for over $90 \%$ of the land price fluctuations. Working through the endogenous credit constraint, the housing demand shock also drives a substantial fraction of fluctuations in investment $(36-46 \%)$ and in output $(22-38 \%)$.

It does not follow that an economic shock directly influencing the borrowing capacity will have an important impact on both asset prices and investment fluctuations. The collateral shock is the case in point: the shock is very persistent and has the third largest standard deviation, but it has little impact on the dynamics of the land price and that its impact on output is modest (about 10\%). The results are evident in Figures 4 and 5 by comparing the relative scales of the two figures: the estimated peak effect of a housing demand shock on the land price exceeds that of a collateral shock by an order of magnitude (0.042 vs. 0.003).

As we have discussed in Section IV, there are two reasons why credit constraints produce much stronger amplification for the housing demand shock than for the collateral shock. First, the housing demand shock directly drives up the household's land demand and the resulting increase in the land price raises the entrepreneur's net worth and therefore the entrepreneur's land demand as well. As the two sectors compete for the fixed amount of land, the land price rises. The rise in the land price raises the collateral value for the entrepreneur and generates a powerful dynamic financial multiplier that amplifies and propagates the initial housing demand shock. In contrast, 
the collateral shock does not shift the household's land demand curve, but only the entrepreneur's demand curve. Consequently, the collateral shock has a smaller effect on the land price than does the housing demand shock.

Second, the collateral shock expands the entrepreneur's borrowing capacity and the resulting increase in leverage reduces the entrepreneur's future net worth. The reduction in future net worth hampers the entrepreneur's ability to invest in productive factors such as land and capital and thus offsets the initial increase in land demand and the land price. In contrast, as we have argued in Section IV, the housing demand shock has a direct impact on the land price and thus on the collateral value. It leads to a persistent increase in the entrepreneur's net worth. Figure 6 confirms this intuition. The figure shows that a positive housing demand shock leads to a persistent increase in the entrepreneur's net worth, whereas a positive collateral shock leads a small initial increase and subsequent persistent declines in the net worth.

VI.3. The housing price and real aggregate variables. Some empirical studies document positive comovements between the housing price and consumption (Campbell and Mankiw, 1989; Zeldes, 1989; Case, Quigley, and Shiller, 2005). These comovements are consistent with our findings (see, for example, the impulse responses to the technology, collateral, and housing shocks in Figures 3-5). But the question of how important these comovements are relative to the comovements between the housing price and business investment remains unanswered. In this section, we address this important question by comparing our model results with the data.

We begin with the data. The first column of Figure 7 reports the impulse responses of the housing price and consumption in response to a shock to the housing price series, estimated from the same recursive bivariate BVAR model as in the first column of Figure 1, except that investment is now replaced by consumption. A comparison of the first columns in these two figures reveals that while consumption and the housing price move together, the size of these comovements is not nearly as important as the comovements between investment and the housing price.

We now show that the two types of financial shocks - the collateral shock and the housing demand shock - identified in our structural model can explain most of these facts. For this purpose, we need to calculate what would have happened if only the financial shocks had occurred throughout the history. Since our model is structural, it is internally coherent to perform the counterfactual exercise by turning off all the estimated structural shocks bar the two types of financial shocks and then using our estimated model to generate the time paths of the housing price, consumption, and 
investment by conditioning on the estimated initial state variables and the estimated sequence of financial shocks. We then compare the simulation to the data.

The second column of Figure 1 reports the impulse responses of the housing price and investment based on the simulated data from the DSGE model conditioned on the historical housing demand shock only. The third column reports the same set of impulse responses based on the simulated data conditioned on both the housing demand shock and the collateral shock. The way the impulse responses are calculated is exactly the same as the bivariate BVAR applied to the actual data. Note that the BVAR is a statistical, atheoretical device used only for the purpose of summarizing the comovements between an aggregate real variable and the housing price. By construction, had all the other shocks in our DSGE model been left in place, the simulations would have matched the observed data exactly and the impulse responses from the BVAR applied to these simulated data would have been exactly the same as those in the data reported in the first column of the figure. Thus, the differences between the first column and the second (third) column reflect the missing histories contributed by the shocks other than the housing demand shock (the financial shocks).

Figure 1 shows that the magnitude of investment responses implied by the simulated data conditioned on the housing demand shock only would be much stronger than that implied by the data. Together with the collateral shock, however, the model is able to generate the magnitude of investment responses and the persistent comovements between the housing price and business investment comparable to the data. The results indicate that the two types of financial shocks, working through the endogenous creditconstraint channel, can explain most of the comovements between the housing price and investment observed in the data.

The second column of Figure 7 reports the impulse responses of the housing price and consumption implied by the simulated data conditioned on the housing demand shock only and the third column reports those implied by the simulations conditioned on both financial shocks. Again, the financial shocks in our structural model explain most of the observed comovements between the housing price and consumption.

In summary, the financial shocks identified in our structural model explain most of the observed comovements between the housing price and real aggregate variables. Based on the simulated time series conditioned on the two types of financial shocks in our model, we are able to reproduce the impulse responses of business investment that are much larger than the responses of consumption, as we document in the U.S. data. 


\section{Conclusion}

We have established that credit constraints can substantially amplify and propagate macroeconomic fluctuations in a DSGE framework. We argue that, for credit constraints to play an important role in macroeconomic fluctuations, the model needs to have a mechanism to explain the observed positive and persistent comovements between housing prices and business investment. We have identified such a mechanism. By matching these comovements, we demonstrate that the financial channel through credit constraints, as developed by by Kiyotaki and Moore (1997), is not only theoretically elegant but also empirically important.

To focus on our main message that credit constraints provide an important transmission mechanism, our analysis abstracts from a number of factors to which our model can be extended in future research. One extension is to apply our analysis to a broader set of collateral assets such as intangible and working capital. Another ambitious task is to extend our model to an explicit evaluation of policy intervention in the throes of financial crisis. 
TABLE 1. Prior distributions and posterior modes of structural parameters

\begin{tabular}{lllllllllll}
\hline \hline & \multicolumn{3}{c}{ Prior } & & & & & \multicolumn{3}{c}{ Posterior } \\
\cline { 2 - 5 } \cline { 8 - 10 } Parameter & Distribution & $\mathrm{a}$ & $\mathrm{b}$ & Low & High & & Mode & Low & High \\
\hline$\gamma_{h}$ & Beta(a,b) & 1.00 & 2.00 & 0.025 & 0.776 & & 0.4655 & 0.4176 & 0.5340 \\
$\gamma_{e}$ & Beta(a,b) & 1.00 & 2.00 & 0.025 & 0.776 & & 0.6050 & 0.3577 & 0.8074 \\
$\Omega$ & Gamma(a,b) & 1.00 & 0.50 & 0.102 & 5.994 & & 0.1881 & 0.1614 & 0.2646 \\
$100\left(g_{\gamma}-1\right)$ & Gamma(a,b) & 1.86 & 3.01 & 0.100 & 1.500 & & 0.3682 & 0.2411 & 0.4652 \\
$100\left(\bar{\lambda}_{q}-1\right)$ & Gamma(a,b) & 1.86 & 3.01 & 0.100 & 1.500 & & 1.2530 & 1.1035 & 1.3776 \\
\hline$\beta$ & Simulated & & & 0.9563 & 0.9946 & & 0.9870 & 0.9844 & 0.9905 \\
$\bar{\lambda}_{a}$ & Simulated & & & 0.0000 & 0.0509 & & 0.0068 & 0.0020 & 0.0105 \\
$\bar{\varphi}$ & Simulated & & & 0.0000 & 0.0697 & & 0.0497 & 0.0424 & 0.0593 \\
$\phi$ & Simulated & & & 0.0655 & 0.0701 & & 0.0697 & 0.0694 & 0.0700 \\
$\delta$ & Simulated & & & 0.0291 & 0.0485 & & 0.0369 & 0.0354 & 0.0391 \\
$\alpha$ & Calibrated & & & & & & 0.3000 & 0.3000 & 0.3000 \\
$\bar{\theta}$ & Calibrated & & & & & & 0.7500 & 0.7500 & 0.7500 \\
\hline
\end{tabular}

Note: "Low" and "High" denote the bounds of the $90 \%$ probability interval for the prior distribution. 
TABle 2. Prior Distributions and posterior modes of shock parameters

\begin{tabular}{|c|c|c|c|c|c|c|c|c|}
\hline \multirow[b]{2}{*}{ Parameter } & \multicolumn{3}{|c|}{ Prior } & \multirow[b]{2}{*}{ Low } & \multirow[b]{2}{*}{ High } & \multicolumn{3}{|c|}{ Posterior } \\
\hline & Distribution & $\mathrm{a}$ & $\mathrm{b}$ & & & Mode & Low & High \\
\hline$\rho_{a}$ & $\operatorname{Beta}(a, b)$ & 1.0000 & 2.0000 & 0.0256 & 0.7761 & 0.9108 & 0.8558 & 0.9327 \\
\hline$\rho_{z}$ & $\operatorname{Beta}(a, b)$ & 1.0000 & 2.0000 & 0.0256 & 0.7761 & 0.4743 & 0.2899 & 0.6143 \\
\hline$\rho_{\nu_{z}}$ & $\operatorname{Beta}(a, b)$ & 1.0000 & 2.0000 & 0.0256 & 0.7761 & 0.0074 & 0.0081 & 0.4428 \\
\hline$\rho_{q}$ & $\operatorname{Beta}(a, b)$ & 1.0000 & 2.0000 & 0.0256 & 0.7761 & 0.6078 & 0.4989 & 0.7003 \\
\hline$\rho_{\nu_{q}}$ & $\operatorname{Beta}(a, b)$ & 1.0000 & 2.0000 & 0.0256 & 0.7761 & 0.2920 & 0.0711 & 0.6215 \\
\hline$\rho_{\varphi}$ & $\operatorname{Beta}(a, b)$ & 1.0000 & 2.0000 & 0.0256 & 0.7761 & 0.9998 & 0.9988 & 0.9999 \\
\hline$\rho_{\psi}$ & $\operatorname{Beta}(a, b)$ & 1.0000 & 2.0000 & 0.0256 & 0.7761 & 0.9799 & 0.9708 & 0.9914 \\
\hline$\rho_{\theta}$ & $\operatorname{Beta}(a, b)$ & 1.0000 & 2.0000 & 0.0256 & 0.7761 & 0.9790 & 0.9736 & 0.9876 \\
\hline$\sigma_{a}$ & Inverse gamma $(a, b)$ & 0.3543 & 0.0002 & 0.0001 & 1.0000 & 0.1387 & 0.0955 & 0.5453 \\
\hline$\sigma_{z}$ & Inverse gamma $(a, b)$ & 0.3543 & 0.0002 & 0.0001 & 1.0000 & 0.0036 & 0.0028 & 0.0046 \\
\hline$\sigma_{\nu_{z}}$ & Inverse gamma $(a, b)$ & 0.3543 & 0.0002 & 0.0001 & 1.0000 & 0.0038 & 0.0034 & 0.0049 \\
\hline$\sigma_{q}$ & Inverse gamma $(a, b)$ & 0.3543 & 0.0002 & 0.0001 & 1.0000 & 0.0037 & 0.0031 & 0.0045 \\
\hline$\sigma_{\nu_{q}}$ & Inverse gamma $(a, b)$ & 0.3543 & 0.0002 & 0.0001 & 1.0000 & 0.0025 & 0.0019 & 0.0032 \\
\hline$\sigma_{\varphi}$ & Inverse gamma $(a, b)$ & 0.3543 & 0.0002 & 0.0001 & 1.0000 & 0.0543 & 0.0500 & 0.0655 \\
\hline$\sigma_{\psi}$ & Inverse gamma $(a, b)$ & 0.3543 & 0.0002 & 0.0001 & 1.0000 & 0.0073 & 0.0067 & 0.0087 \\
\hline$\sigma_{\theta}$ & Inverse gamma $(a, b)$ & 0.3543 & 0.0002 & 0.0001 & 1.0000 & 0.0126 & 0.0116 & 0.0144 \\
\hline
\end{tabular}

Note: "Low" and "High" denote the bounds of the $90 \%$ probability interval for the prior distribution. 
TABLE 3. Variance decompositions of aggregate quantities

\begin{tabular}{|c|c|c|c|c|c|c|c|c|}
\hline Horizon & Patience & Ngrowth & Nlevel & Bgrowth & Blevel & Housing & Labor & Collateral \\
\hline \multicolumn{9}{|c|}{ land price } \\
\hline $1 Q$ & 3.86 & 1.14 & 1.12 & 0.01 & 0.01 & 91.94 & 1.90 & 0.01 \\
\hline $4 Q$ & 3.15 & 1.99 & 0.29 & 0.04 & 0.01 & 92.79 & 1.66 & 0.08 \\
\hline $8 Q$ & 2.80 & 2.47 & 0.19 & 0.06 & 0.00 & 92.53 & 1.77 & 0.18 \\
\hline $16 \mathrm{Q}$ & 2.23 & 3.22 & 0.14 & 0.04 & 0.00 & 92.17 & 1.95 & 0.25 \\
\hline $24 \mathrm{Q}$ & 1.75 & 3.80 & 0.11 & 0.10 & 0.00 & 92.08 & 1.95 & 0.20 \\
\hline \multicolumn{9}{|c|}{ Consumption } \\
\hline $1 Q$ & 5.91 & 42.49 & 6.85 & 0.26 & 0.12 & 1.08 & 42.32 & 0.97 \\
\hline $4 Q$ & 2.05 & 55.84 & 1.33 & 0.38 & 0.03 & 1.24 & 38.74 & 0.39 \\
\hline $8 Q$ & 1.28 & 53.87 & 1.17 & 0.59 & 0.01 & 6.67 & 34.47 & 1.95 \\
\hline $16 Q$ & 2.82 & 52.38 & 1.09 & 0.42 & 0.01 & 10.77 & 29.66 & 2.87 \\
\hline $24 \mathrm{Q}$ & 2.82 & 56.25 & 0.89 & 1.38 & 0.00 & 9.16 & 27.35 & 2.15 \\
\hline \multicolumn{9}{|c|}{ Investment } \\
\hline $1 Q$ & 18.86 & 0.35 & 12.39 & 3.29 & 1.35 & 40.63 & 10.38 & 12.76 \\
\hline $4 \mathrm{Q}$ & 18.44 & 3.21 & 4.36 & 0.87 & 0.25 & 46.46 & 10.28 & 16.11 \\
\hline $8 Q$ & 17.42 & 6.12 & 3.33 & 3.03 & 0.19 & 44.36 & 10.92 & 14.64 \\
\hline $16 Q$ & 15.50 & 9.23 & 2.87 & 8.86 & 0.17 & 39.38 & 11.41 & 12.58 \\
\hline $24 \mathrm{Q}$ & 14.25 & 10.81 & 2.64 & 12.83 & 0.15 & 36.26 & 11.10 & 11.96 \\
\hline \multicolumn{9}{|c|}{ Output } \\
\hline $1 \mathrm{Q}$ & 12.36 & 4.16 & 15.17 & 5.09 & 0.32 & 32.90 & 20.26 & 9.76 \\
\hline $4 \mathrm{Q}$ & 11.71 & 11.89 & 4.49 & 1.84 & 0.06 & 37.90 & 19.19 & 12.92 \\
\hline $8 Q$ & 10.56 & 19.14 & 3.12 & 1.04 & 0.04 & 34.61 & 20.40 & 11.10 \\
\hline $16 Q$ & 8.58 & 29.42 & 2.34 & 1.54 & 0.03 & 27.71 & 22.29 & 8.08 \\
\hline $24 \mathrm{Q}$ & 7.13 & 36.83 & 1.92 & 2.46 & 0.03 & 22.68 & 22.47 & 6.48 \\
\hline
\end{tabular}

Note: Columns 2 to 9 reports the contributions of the patience shock (Patience), the permanent and transitory shocks to the neutral technology (Ngrowth and Nlevel), the permanent and transitory shocks to the biased technology (Bgrowth and Blevel), the housing demand shock (Housing), the labor supply shock (Labor), and the collateral shock (Collateral). 

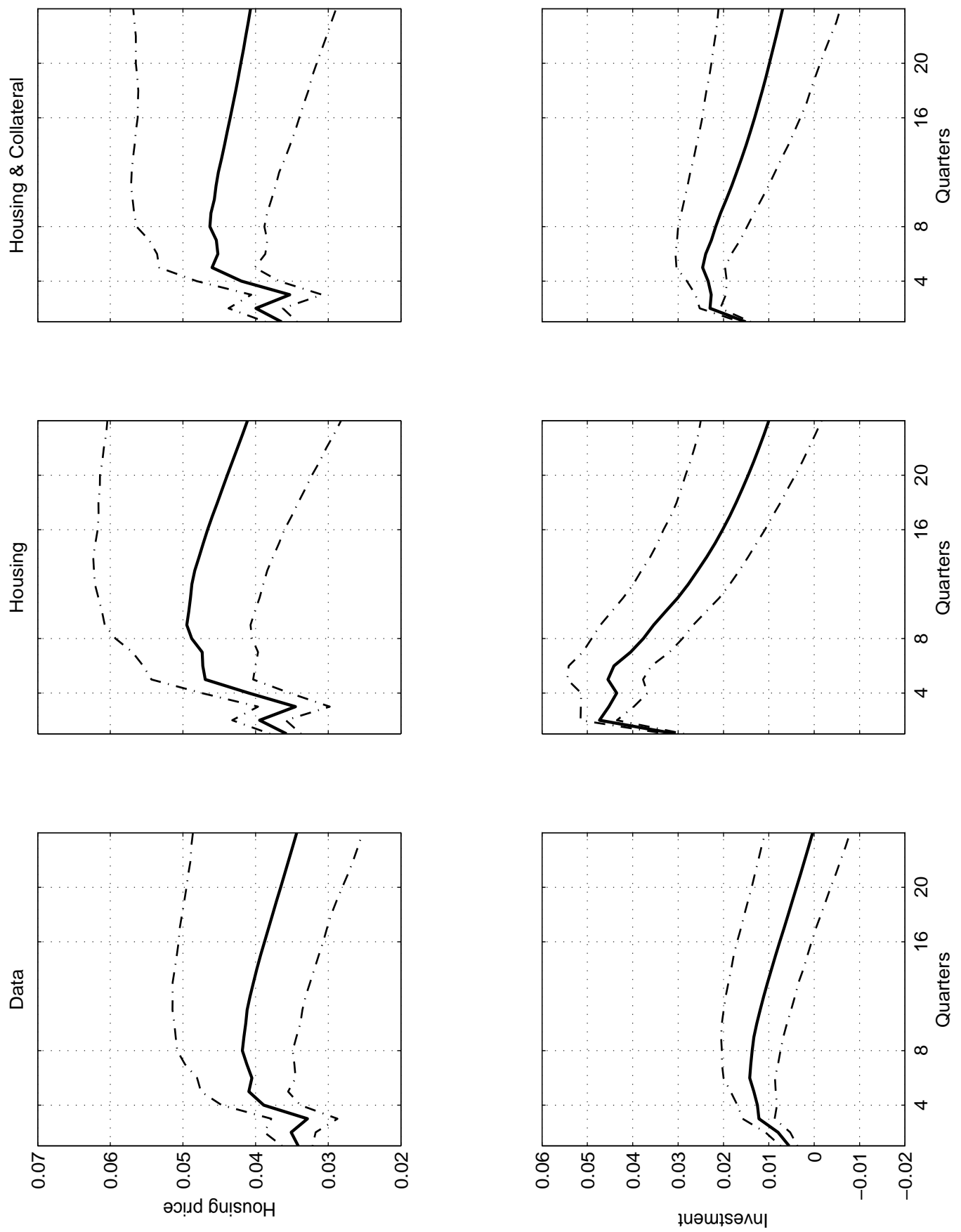

FIGURE 1. Impulse responses from a recursive bivariate BVAR model with the housing price ordered first. Solid lines represent the estimated responses and dotted-dashed lines represent the $68 \%$ probability bands. The first column is based on the actual data. The second column on the counterfactual data generated with housing shocks only. The third column on the counterfactual data generated with both housing and collateral shocks. 


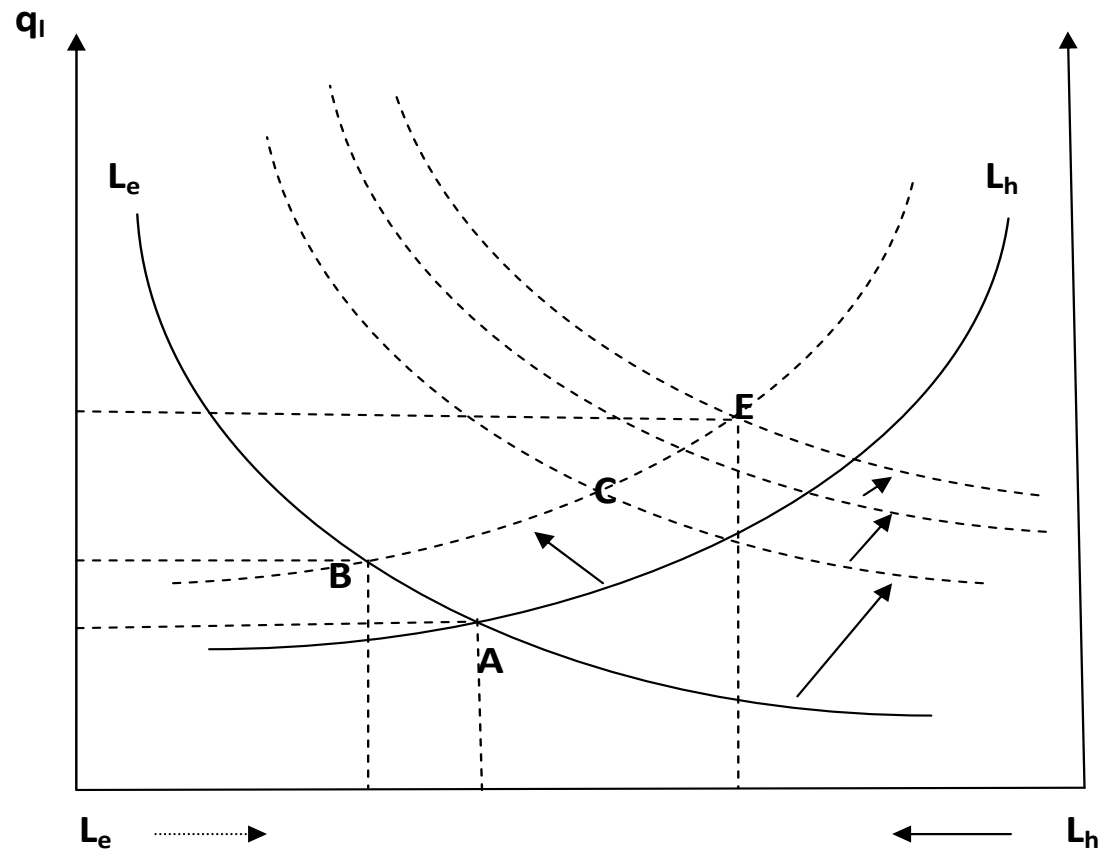

Figure 2. Dynamic financial multiplier: an illustration. $L_{h}$ denotes the household's holding of land, $L_{e}$ denotes the entrepreneur's holding of land, and $q_{l}$ denotes the price of land. 

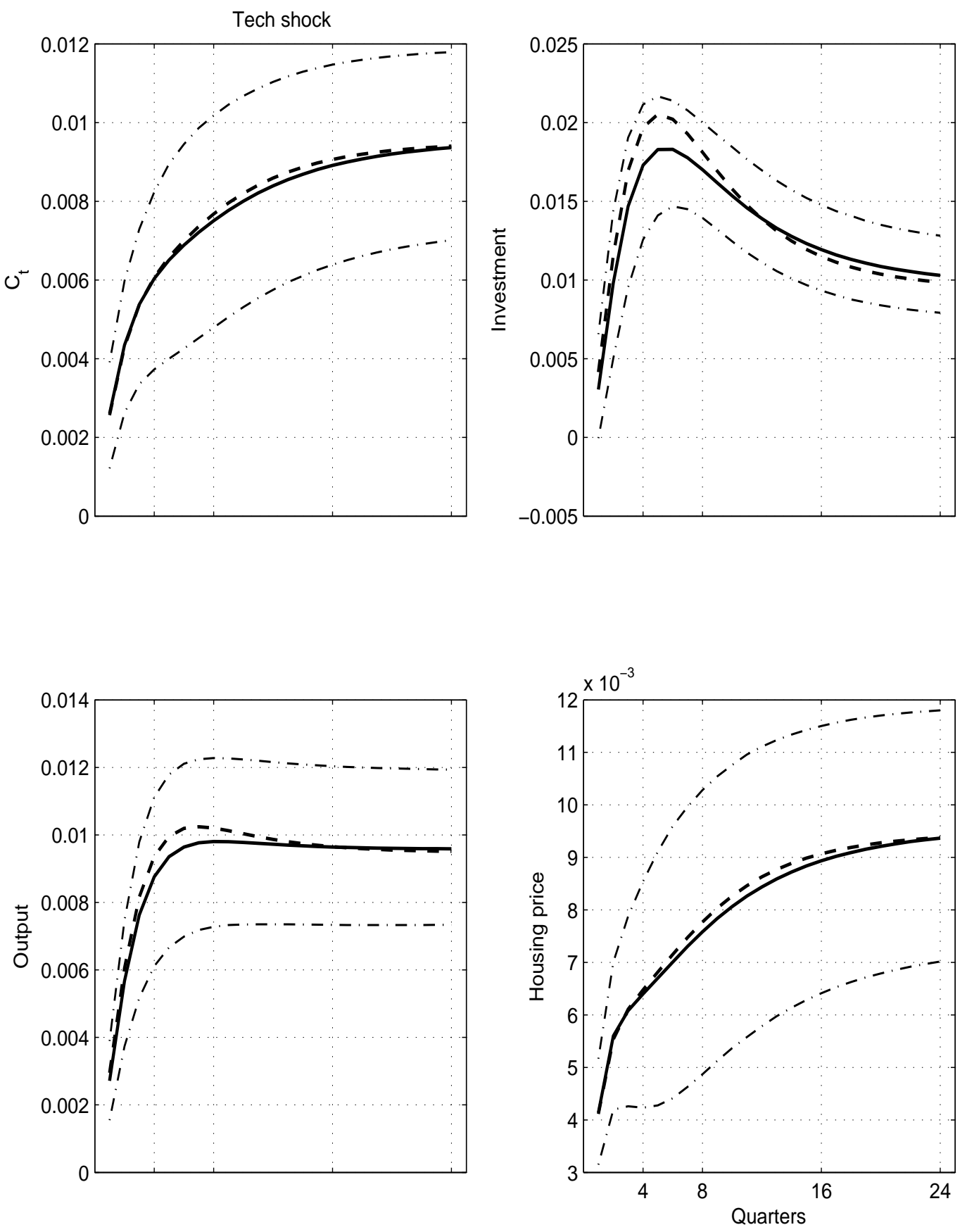

FIGURE 3. Impulse responses to a positive (one-standard-deviation) shock to neutral technology growth. Thick solid lines represent the estimated responses in the economy with the endogenous credit limit and thin dotted-dashed lines give the $68 \%$ probability bands. Thick dashed lines represent the responses in the economy with the fixed credit limit. 

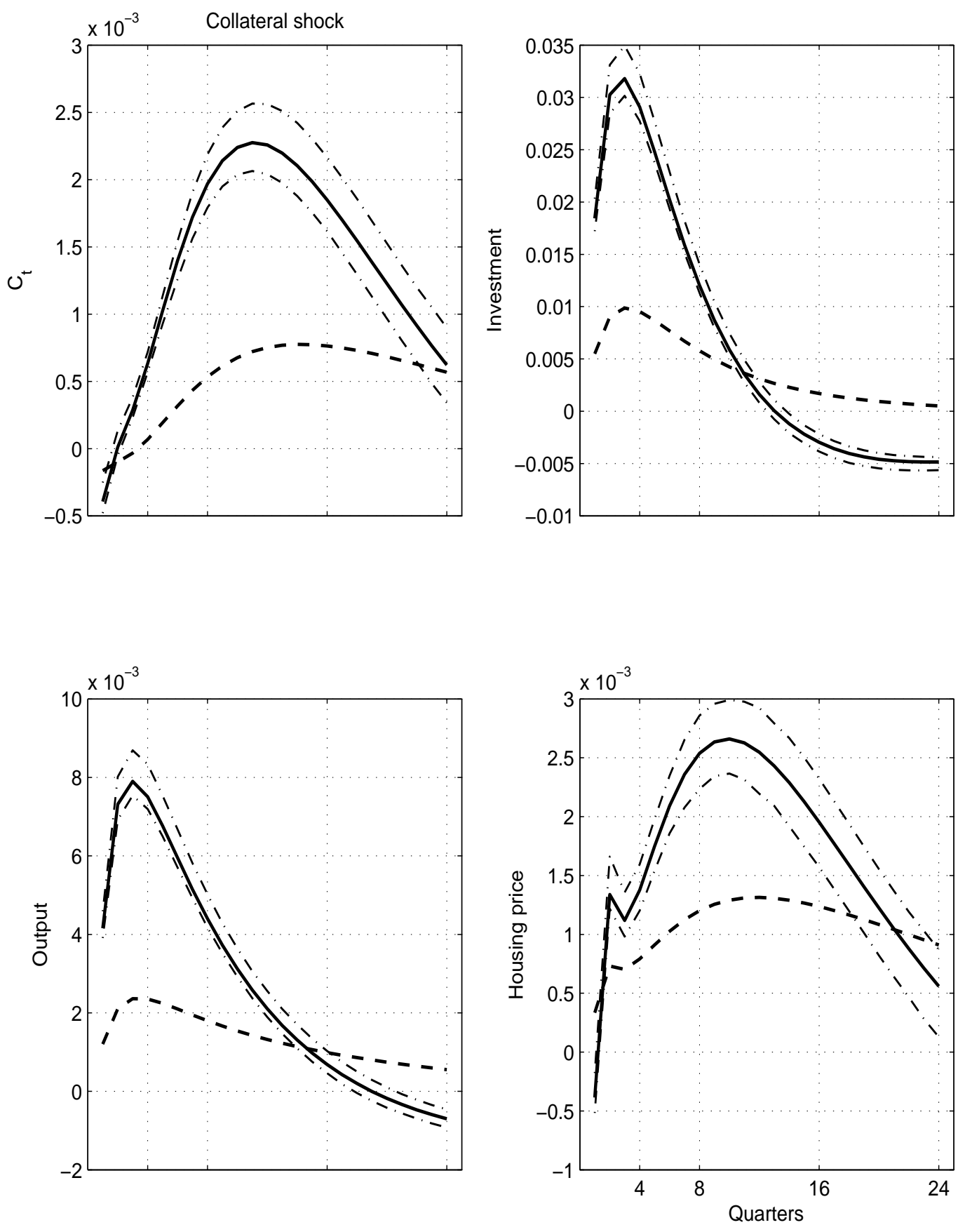

FIGURE 4. Impulse responses to a positive (one-standard-deviation) collateral shock. Thick solid lines represent the estimated responses in the economy with the endogenous credit limit and thin dotted-dashed lines give the $68 \%$ probability bands. Thick dashed lines represent the responses in the economy with the fixed credit limit. 

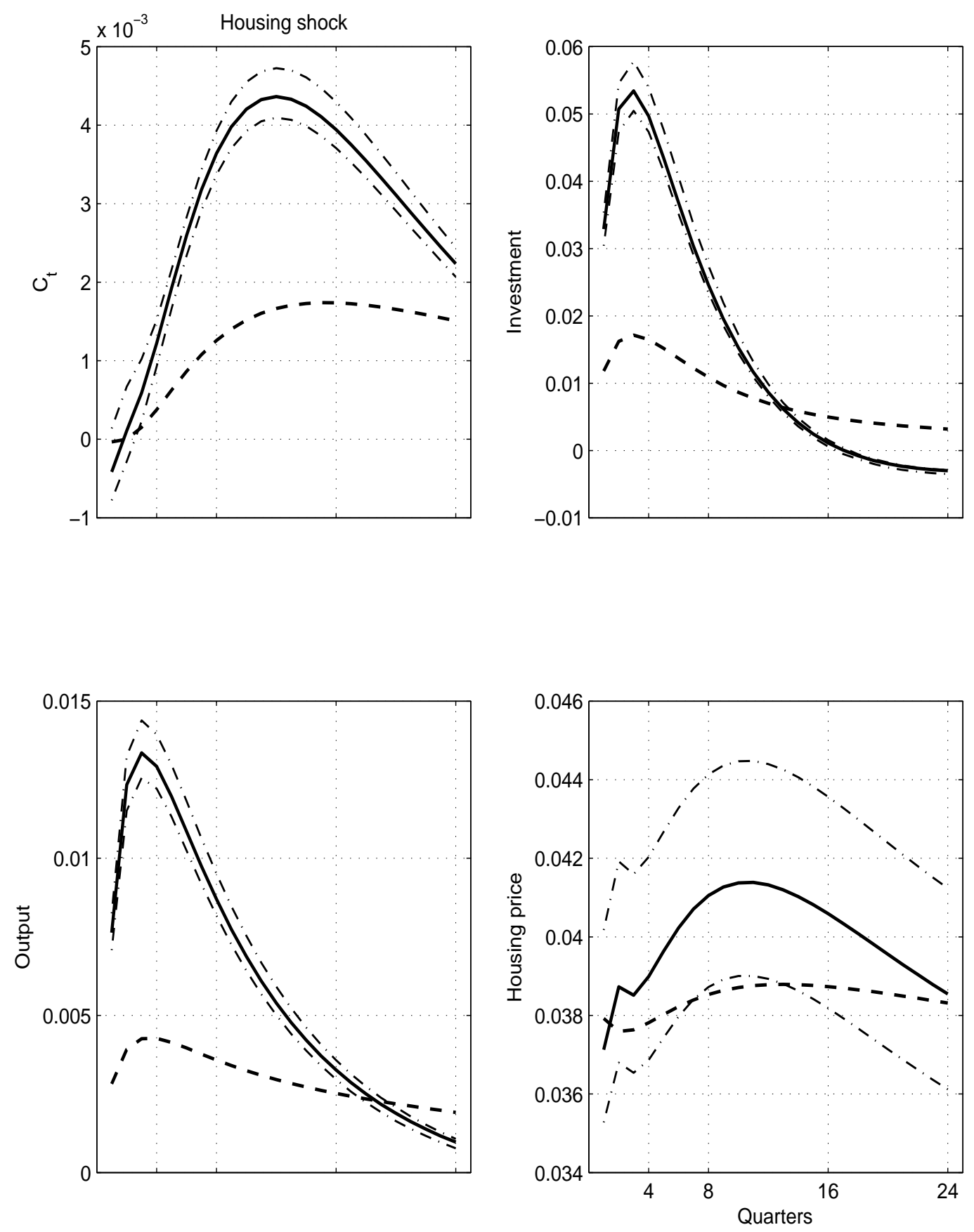

FiguRE 5. Impulse responses to a positive (one-standard-deviation) shock to housing demand. Thick solid lines represent the estimated responses in the economy with the endogenous credit limit and thin dotted-dashed lines give the $68 \%$ probability bands. Thick dashed lines represent the responses in the economy with the fixed credit limit. 

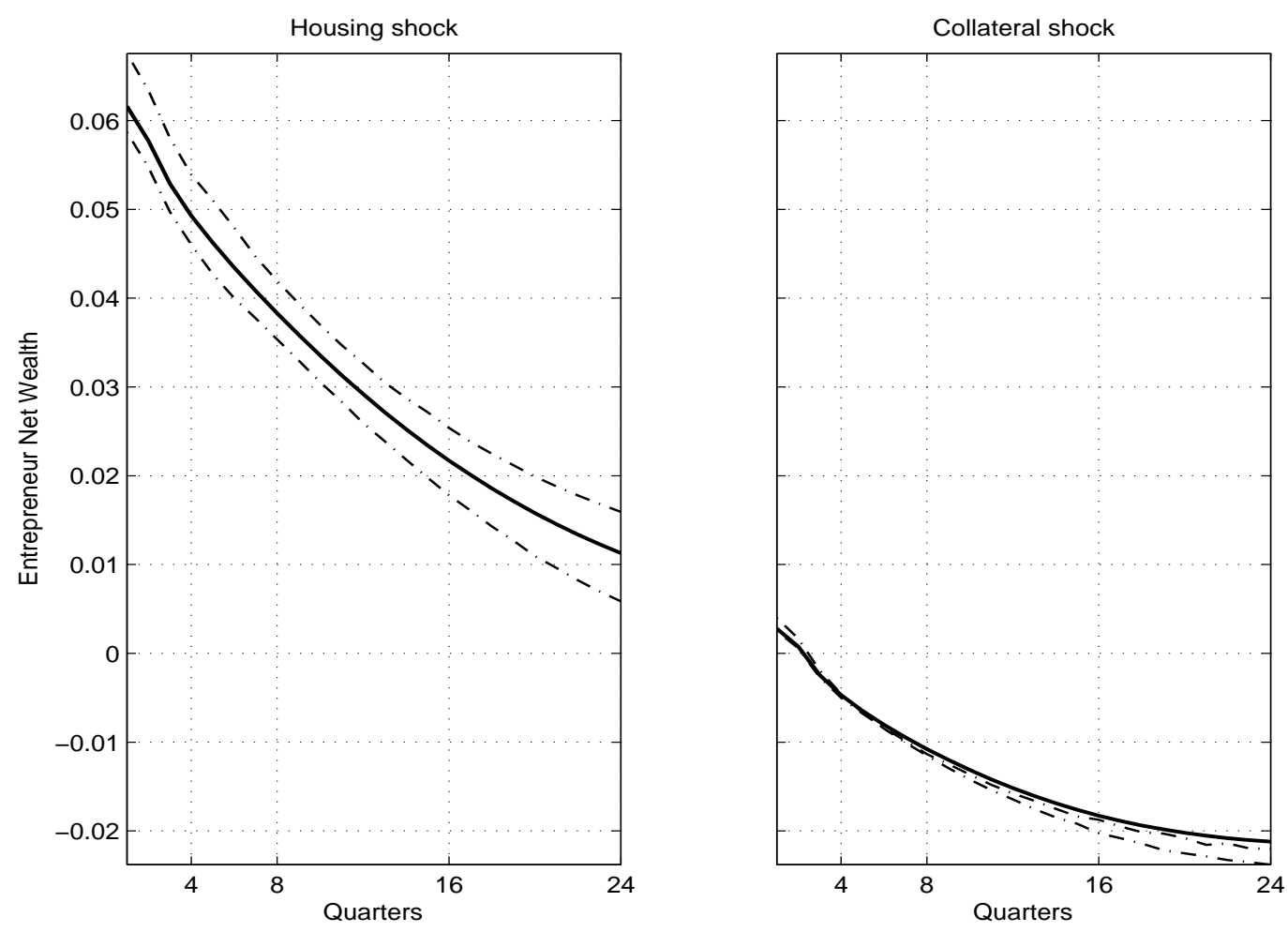

FIgURE 6. Impulse responses to the entrepreneur's net worth to a positive, one-standard-deviation, shock to housing demand (left panel) and to a positive, one-standard-deviation, collateral shock (right panel). Thick solid lines represent the estimated responses from the model with the endogenous credit limit and thin dotted-dashed lines give the $68 \%$ probability bands. 

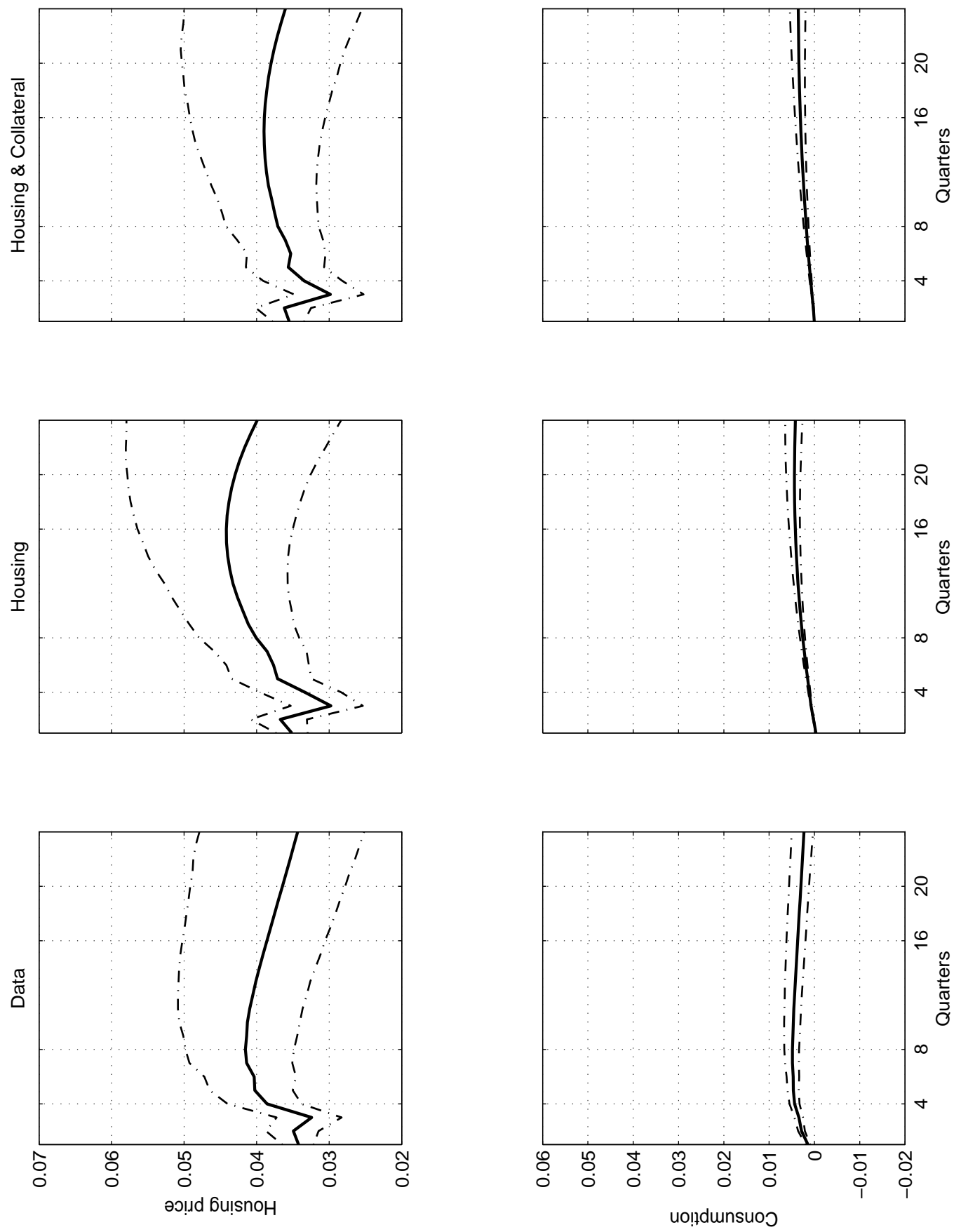

FigURE 7. Impulse responses from a recursive bivariate BVAR model with the housing price ordered first. Solid lines represent the estimated responses and dotted-dashed lines represent the $68 \%$ probability bands. The first column is based on the actual data. The second column on the counterfactual data simulated with housing shocks only. The third column on the counterfactual data generated with both housing and collateral shocks. 


\section{Appendix A. DAta Description}

All data are either taken directly from the Haver Analytics Database or constructed by Patrick Higgins at the Federal Reserve Bank of Atlanta. The construction methods are described below.

The model estimation is based on six U.S. aggregate variables: the relative price of land $\left(q_{l t}^{\text {Data }}\right)$, the inverse of the relative price of investment $\left(Q_{t}^{\text {Data }}\right)$, real per capita consumption $\left(C_{t}^{\text {Data }}\right)$, real per capita investment in consumption units $\left(I_{t}^{\text {Data }}\right)$, real per capita nonfinancial business debt $\left(B_{t}^{\text {Data }}\right)$, and per capita hours $\left(L_{t}^{\text {Data }}\right)$. All these series are constructed to be consistent with the corresponding series in Greenwood, Hercowitz, and Krusell (1997), Cummins and Violante (2002), and Davis and Heathcote (2007).

These series are defined as follows:

- $q_{l t}^{\text {Data }}=\frac{\text { LiqLAND_PI_OFHEO }}{\text { PriceNonDurPlusServExHous }}$;

- $Q_{t}^{\text {Data }}=\frac{\text { PriceNonDurPlusServExHous }}{\text { GordonPriceCDplusES }}$

- $C_{t}^{\text {Data }}=\frac{(\text { NomConsNHSplusND)/PriceNonDurPlusServExHous }}{\text { LNNReviseQtr }}$;

- $I_{t}^{\text {Data }}=\frac{(\text { CD@USECON }+ \text { FNE@USECON }) / \text { PriceNonDurPlusServExHous }}{\text { LNNReviseQtr }}$

- $B_{t}^{\text {Data }}=\frac{(\text { PL10TCR5@FFUNDS }+ \text { PL11CRE5@FFUNDS) } / \text { PriceNonDurPlusServExHous }}{\text { LNNReviseQtr }}$

- $L_{t}^{\text {Data }}=\frac{\text { LXNFH@USECON }}{\text { LNNReviseQtr }}$.

The original data, the constructed data, and their sources are described below.

LNNReviseQtr: civilian noninstitutional population with ages 16 years and over (NSA, Thous) by eliminating breaks in population from 10-year censuses and post 2000 American Community Surveys using "error of closure" method. This fairly simple method is used by the Census Bureau to get a smooth monthly population series to reduce the unusual influence of drastic demographic changes. The detailed explanation can be found in

http://www.census.gov/popest/archives/methodology/intercensal_nat_meth.html. Source: BLS.

PriceNonDurPlusServExHous: the consumption deflator. The Tornqvist procedure is used to construct this deflator as a weighted aggregate index from nondurables consumption and services consumption excluding housing services. Source: BEA.

LiqLAND_PI_OFHEO: the liquidity-adjusted price index for residential land from Davis and Heathcote (2007) ( http://www.marginalq.com/morris/landdata.html). The adjustment methods of Quart and Quigley $(1989,1991)$ are used to be consistent with the volatility measure provided by Lin and Liu (2008). 
GordonPriceCDplusES: the quality-adjusted price index for consumer durable goods, equipment investment, and software investment. This index is a weighted one from a number of individual price series within this category. For each individual price series from 1947 to 1983, we use Gordon (1990)'s quality-adjusted price index. Following Cummins and Violante (2002), we estimate an econometric model of Gordon's price series as a function of a time trend and a few macroeconomic indicators in the National Income and Product Account (NIPA), including the current and lagged values of the corresponding NIPA price series; the estimated coefficients are then used to extrapolate the qualityadjusted price index for each individual price series for the sample from 1984 to 2008. These constructed price series are annual. We use Denton (1971)'s method to interpolate these annual series on a quarterly frequency. We then use the Tornquist procedure to construct the quality-adjusted price index from the interpolated individual quarterly price series. Source: BEA.

NomConsNHSplusND: nominal personal consumption expenditures: non-housing services and nondurable goods. Source: BEA.

CD@USECON: nominal personal consumption expenditures: durable goods. Source: BEA.

FNE@USECON: nominal private nonresidential investment: equipment \& software. Source: BEA.

PL10TCR5@FFUNDS: nonfarm nonfinancial corporation business liabilities: credit market debt. Source: BEA.

PL11CRE5@FFUNDS: nonfarm nonfinancial noncorporate business liabilities: credit market instruments. Source: BEA.

LXNFH@USECON: nonfarm business sector: hours of all persons (1992=100). Source: BLS. 


\section{REFERENCES}

Aoki, K., G. Benigno, And N. Kiyotaki (2007): "Capital Flows and Asset Prices," Unpublished Manuscript, Princeton University.

Aoki, K., J. Proudman, and G. Vlieghe (2004): "House Prices, Consumption, and Monetary Policy: A Financial Accelerator Approach," Journal of Financial Intermediation, 13, 414-435.

Bernanke, B. S., M. Gertler, and S. Gilchrist (1999): "The Financial Accelerator in a Quantitative Business Cycle Framework," in The Handbook of Macroeconomics, ed. by J. B. Taylor, and M. Woodford, pp. 1341-1393. Elsevier Science B.V., Amsterdam, North Holland.

Boldrin, M., L. J. Christiano, and J. D. Fisher (2001): "Habit Persistence, Asset Returns, and the Business Cycle," American Economic Review, 91(1), 149 166.

Bond, S. R., And J. G. Cummins (2000): "The Stock Market and Investment in the New Economy: Some Tangible Facts and Intangible Fictions," Brookings Papers on Economic Activity, 2, 61-108.

Campbell, J. Y., And N. G. MankiW (1989): "Consumption, Income, and Interest Rates: Reinterpreting the Time Series Evidence," in NBER Macroeconomics Annual, ed. by O. J. Blanchard, and S. Fischer, vol. 4, pp. 185-216. MIT Press, Cambridge, MA.

Carlstrom, C. T., And T. S. Fuerst (1997): "Agency Costs, Net Worth, and Business Fluctuations: A Computable General Equilibrium Analysis," American Economic Review, 87(5), 893-910.

Case, K., J. Quigley, And R. Shiller (2005): "Comparing Wealth Effects: The Stock Market versus the Housing Market," Advances in Macroeconomics, Berkeley Electronic Press, 5(1), 1-32.

Chaney, T., D. Sraer, and D. Thesmar (2008): "The Collateral Channel: How Real Estate Shocks affect Corporate Investment," Manuscript, University of Chicago.

Christiano, L., M. Eichenbaum, and C. Evans (2005): "Nominal Rigidities and the Dynamics Effects of a Shock to Monetary Policy," Journal of Political Economy, $113,1-45$.

Christiano, L., R. Motto, and M. Rostagno (2008): "Financial Factors in Economic Fluctuations," Manuscript, Northwestern University.

Christiano, L. J., M. Trabandt, and K. Walentin (2007): "Introducing Financial Frictions and Unemployment into a Small Open Economy Model," Manuscript, 
Sveriges Riksbank Working Paper Series No. 214.

Cooley, T., R. Marimon, and V. Quadrini (2004): "Aggregate Consequences of Limited Contract Enforceability," Journal of Political Economy, 112(4), 817-847.

Cordoba, J.-C., And M. Ripold (2004): "Credit Cycles Redux," International Economic Review, 45(4), 1011-1046.

Cummins, J. G., and G. L. Violante (2002): "Investment-Specific Technical Change in the United States (1947-2000): Measurement and Macroeconomic Consequences," Review of Economic Dynamics, 5, 243-284.

Davis, M. A., And J. Heathcote (2007): "The Price and Quantity of Residential Land in the United States," Journal of Monetary Economics, 54, 2595Ü-2620.

De Fiore, F., And H. Uhlig (2005): "Bank finance versus bond finance: what explains the differences between US and Europe?," European Central Bank Working Paper 547.

Del Negro, M., and F. Schorfheide (2008): "Forming Priors for DSGE Models (and How It Affects the Assessment of Nominal Rigidities)," Journal of Monetary Economics, pp. 1191-1208.

Denton, F. T. (1971): "Adjustment of Monthly or Quarterly Series to Annual Totals: An Approach Based on Quadratic Minimization," Journal of the American Statistical Association, 66, 99-102.

Fisher, I. (1933): "The Debt-Deflation Theory of Great Depressions," Econometrica, $1(4), 337-357$.

Fisher, J. D. M. (2006): "The Dynamic Effects of Neutral and Investment-Specific Technology Shocks," Journal of Political Economy, 114(3), 413-451.

Gale, D., and M. Hellwig (1985): "Incentive-Compatible Debt Contracts: The One-Period Problem," Review of Economic Studies, 52, 647-663.

Gertler, M., S. Gilchrist, and F. M. Natalucci (2007): "External Constraints on Monetary Policy," Journal of Money, Credit and Banking, 39, 295-330.

Gertler, M., And N. Kiyotaki (2009): "Financial Intermediation and Credit Policy in Business Cycle Analysis," Manuscript, Princeton University.

Gilchrist, S., A. Ortiz, and E. Zakrajsek (2009): "Credit Risk and the Macroeconomy: Evidence from an Estimated DSGE Model," Unpublished manuscript, Boston University.

Gordon, R. J. (1990): The Measurement of Durable Goods Prices. University of Chicago Press, Chicago,Illinois. 
Greenwood, J., Z. Hercowitz, and P. Krusell (1997): "Long-Run Implications of Investment-Specific Technological Change," American Economic Review, 87, 342362.

Hall, R. E. (2001): "The Stock Market and Capital Accumulation," American Economic Review, 91, 1185-1202.

Huggett, M., G. Ventura, And A. Yaron (2009): "Sources of Lifetime Inequality," Manscript.

IAcoviello, M. (2005): "House Prices, Borrowing Constraints, and Monetary Policy in the Business Cycle," American Economic Review, 95(3), 739-764.

Iacoviello, M., ANd S. Neri (2009): "Housing Market Spillovers: Evidence from an Estimated DSGE Model," American Economic Journal: Macroeconomics, (forthcoming).

JERMAnN, U., AND V. QUADRINi (2009): "Macroeconomic Effects of Financial Shocks," Unpublished Manuscript, Wharton School of Business.

Justiniano, A., And G. E. Primiceri (2008): "The Time Varying Volatility of Macroeconomic Fluctuations," American Economic Review, 98(3), 604-641.

Justiniano, A., and G. E. P. A. Tambalotti (2009): "Investment Shocks and the Relative Price of Investment," Manuscript.

Kiyotaki, N. (1998): "Credit and Business Cycles," Japanese Economic Review, 49, $18-35$.

Kiyotaki, N., And J. Moore (1997): "Credit Cycles," Journal of Political Economy, $105(2), 211-248$.

Kocherlakota, N. (2000): "Creating Business Cycles Through Credit Constraints," Federal Reserve Bank of Minneapolis Quarterly Review, 24(3), 2-10.

- (2008): "Exploding Bubbles in a Macroeconomic Model," Manuscript, Federal Reserve Bank of Minneapolis and University of Minnesota.

Krishnamurthy, A. (2003): "Collateral Constraints and the Amplification Mechanism," Journal of Economic Theory, 111, 277-292.

Krusell, P., L. E. Ohanian, J. V. Ríos-Rull, and G. L. Violante (2000): "Capital-Skill Complementarity and Inequality: A Macroeconomic Analysis," Econometrica, 68(5), 1029-1053.

Lin, Z., AND Y. LiU (2008): "Real Estate Returns and Risk with Heterogeneous Investors," Real Estate Economics, 36, 753-776.

Liu, Z., D. F. Waggoner, And T. Zha (2009): "Sources of the Great Moderation: Shocks, Frictions, or Monetary Policy?," Federal Reserve Bank of San Francisco, 
Working Paper 2009-01.

LiU, Z., P. Wang, And T. Zha (2009a): "Asset Pricing and Income Inequality in a Heterogeneous Agent Production Economy," Manuscript.

- (2009b): "A Theory of Housing Demand Shocks," Manuscript.

Lorenzoni, G. (2008): "Inefficient Credit Booms," Review of Economic Studies, 75(3), 809-833.

Lorenzoni, G., And K. Walentin (2007): "Financial Frictions, Investment and Tobin's q," Manuscript, MIT.

MendozA, E. G. (2008): "Sudden Stops, Financial Crises and Leverage: A Fisherian Deflation of Tobin's Q," NBER Working Paper 14444.

Pintus, P. A., And Y. Wen (2008): "Excessive Demand and Boom-Bust Cycles," Federal Reserve Bank of St. Louis Working Paper 2008-014B.

Quart, D. C., And J. M. Quigley (1989): "Inferring an Investment Return Series for Real Estate from Observations on Sales," Real Estate Economics, 17(2), 218-230.

- (1991): "Price Formation and the Appraisal Function in Real Estate Markets," Journal of Real Estate Finance \& Economics, 4(2), 127-146.

Sims, C. A., And T. Zha (1998): "Bayesian Methods for Dynamic Multivariate Models," International Economic Review, 39(4), 949-968.

Smets, F., And R. Wouters (2007): "Shocks and Frictions in US Business Cycles: A Bayesian DSGE Approach," American Economic Review, 97, 586-606.

Townsend, R. (1979): "Optimal Contracts and Competitive Markets with Costly State Verification," Journal of Economic Theory, 21, 265-293.

Zeldes, S. P. (1989): "Consumption and Liquidity Constraints: An Empirical Investigation," Journal of Political Economy, 97, 305-346.

Federal Reserve Bank of San Francisco, Hong Kong University of Science and Technology, Federal Reserve Bank of Atlanta and Emory University 